\title{
Jordi Hernich. Una visión de Barcelona y su espacio público
}

\author{
DOI: https://doi.org/10.1344/waterfront2019.61.6.7
}

\author{
Celeste Pereira Cubilla. Asociación Arquitectos del Paraguay.celeste.pc@hotmail.com \\ Jordi Henrich. Arquitecto. henrich@coac.cat/www.jordihenrich.com
}

Recibido 18 de Mayo de 2018 Evaluado: 5 Septiembre de 2018 Publicado: 30 mayo de 2019.

\section{Resumen}

Jordi Henrich ha sido uno de los protagonistas del desarrollo del espacio público de Barcelona a lo largo de más de dos décadas, tanto desde su actividad como arquitecto municipal, arquitecto del Área Metropolitana de Barcelona y su actividad profesional privada. Este artículo estudia las características del espacio público - las que tiene y las que debería tener - a través de la mirada de este arquitecto hacedor de la Barcelona que puede quedar englobada en el denominado "Modelo Barcelona". Está organizado a modo de entrevista que ha sido editada por el Consejo Editorial de la Revista para ampliar algunas referencias vinculadas con el desarrollo de los contenidos del artículo.

Palabras clave: Jordi Henrich; Barcelona; Espacio Público; Diseño Urbano; Arte Público

\section{Abstract}

Jordi Henrich has been one of the protagonists of the development of the public space of Barcelona over more than two decades, both from his activity as municipal architect, architect of the Metropolitan Area of Barcelona and his private professional activity. This article studies the characteristics of the public space- the ones it has and the ones it should have- through the gaze of this architect who creates the Barcelona that can be encompassed in the so-called "Barcelona Model". It is organized as an interview that has been edited by the Editorial Board of the Journal to expand some references related to the development of the contents of the article.

Keywords: Jordi Henrich; Barcelona; Public space; Urban design; Public Art 
Resum

Jordi Henrich ha estat un dels protagonistes del desenvolupament de l'espai públic de Barcelona al llarg de més de dues dècades, tant des de la seva activitat com a arquitecte municipal, arquitecte de l'Àrea Metropolitana de Barcelona i la seva activitat professional privada. Aquest article estudia les característiques de l'espai públic- les que té i les que hauria de tenir- a través de la mirada d'aquest arquitecte creador de la Barcelona que pot quedar englobada en el denominat "Model Barcelona". Està organitzat a manera d'entrevista que ha estat editada pel Consell Editorial de la Revista per ampliar algunes referències vinculades amb el desenvolupament dels continguts de l'article.

Paraules clau: Jordi Henrich; Barcelona; Espai Públic; Disseny Urbà; art Públic

Jordi Henrich nos recibe en su estudio situado en el centro histórico de Barcelona y con vistas al Palau de la Música de Lluis Domènech i Montaner. Tras cordial bienvenida iniciamos la entrevista

¿Cómo definiría Ud. el espacio público?

Primero que nada, muchas gracias por el interés por preguntarme cosas, espero que sea útil. Bueno el espacio público digamos que como que mi trabajo viene del Modelo Barcelona ${ }^{1}$, que se estableció a partir de la estrategia de Oriol Bohigas² a principios de los años '80, que empezó el Ayuntamiento democrático, después de la dictadura, para transformar y regenerar la ciudad.

Bohigas estableció que "una ciudad son sus espacios públicos y sus equipamientos públicos". Por un lado, esto es un pensamiento democrático y por el otro es un pensamiento que podemos decir un poco de izquierdas, en el sentido de que busca calificar la ciudad y ponerla en valor, lo más genuino de cada ciudad y de cada paisaje, a través de lo público. Y esto ya es un establecimiento de una base que tiene que guiar toda la actuación en los espacios públicos.

Afortunadamente aquí los espacios públicos van de fachada a fachada, que en otros países no es exactamente así. Esta estrategia que se inició con este criterio de actuar en los espacios públicos, regenerar la ciudad a partir de los espacios públicos, luego se desarrolla a partir de ciertos criterios importantes que son arquitectónicosante todo.

Por un lado, es la estrategia del proyecto global, proyecto global quiere decir que no es un proyecto parcial o específico de elementos de jardinería, o de movilidad, o de técnicos de pendientes, o de saneamiento, o de infraestructura, sino que es un proyecto global como proyecto arquitectónico, es decir donde todos los condicionantes técnicos, históricos, de contexto, se tienen que tener presentes en un pensamiento global y conla capacidad deelaborar una síntesis de todo esto que favorezcala creación de eseespacio público, que tiene que ser una respuesta al contexto.

Yo creo que incluso más de lo que podemos pedir a un edificio, al que, evidentemente, siempre hay que pedirle una respuesta al contexto, pero un espacio público sí que tiene que estar muy

1.- Respecto al denominado Modelo Barcelona puede consultarse, entre otros, (Borja, Jordi (ed) 1995; Capel, Horacio 2005; Monclús, Fco. Javier 2005; Montaner, J.M.- Alvarez, F- Muxí, Z (ED) 2011; Remesar, A 2013; Borja, Jordi 2009; Lecea, I de- Henrich, J 2002; de Lecea 2006; McNeill, David 1999; Maragall, Pascual 1991; FAVB (Federació de Veins de Barcelona) 1997; Subirós, Pep (Ed) 1993)

2.- Al respeto de la filosofía urbana de Oriol Bohigas, consultar (Bohigas, Oriol 1985; Bohigas, O- Tusquets, O 1986 ; Bohigas, Oriol 2004; Bohigas, O- Puigdomenech,A- ACebillo, J- Galofré, J 1983) 
implicado en su contexto, además, tiene que tener identidad, tiene que aportar identidad. Entonces, este pensamiento de que el espacio público es un proyecto arquitectónico con una visión global es lo más esencial.

Otro elemento esencial de la estrategia de Bohigas, es actuar con proyectos concretos, que se puedan realizar en tiempos más o menos cortos, es decir períodos de 2-5 años, no grandes proyectos urbanísticos o abstractos en el sentido de poco definidos en cuanto a forma arquitectónica o forma de espacio público, sino proyectos concretos que se puedan realizar en períodos cortos que puedan permitir la generación de transformaciones en un tiempo digamos correctamente prudencial.

Otro criterio digamos entrecomillado es el criterio de que "una calle no es una carretera", por tanto, una calle, una avenida, un bulevar, una Diagonal, un Paseo de Gracia, NO es una carretera. Eso es muy importante porque tenemos que pensar que en los años1980 y sobre todo que veníamos de los años 1970, cuando muchas ciudades del mundo -yo creo que casi todas- tuvieron al coche como protagonista. Entonces se hicieron grandes destrozos urbanísticos a partir de la movilidad vehicular. Creación de modelos, digamos de carreteras, de autovías en plenas ciudades. Hasta en Estocolmo hay unos puentes con unos tirabuzones, Barcelona tenía la Plaza de las Glorias que era un tirabuzón de spaguettis, la Plaza Lesseps también era otro problema, y este problema de la movilidad que es común a todas las ciudades y que castiga los espacios peatonales, también castiga la identidad, que destroza espacios, es una de las respuestas importantes de la estrategia de Bohigas.

Otro tema importante es actuar en todos los Distritos de la ciudad, igualando calidades, tanto en el centro - el Barrio Gótico o El Raval - como en las antiguas Villas, como Gracia o Sant Andreu, que son antiguas villas agregadas, así como en la periferia más nueva en Barcelona, el Norte, como Nou Barris, estos barrios que se crearon en los años 1960-1970 a raíz de la inmigración, digamos a partir de bloques, o de un urbanismo hecho a base de bloques para gente obrera pero sin espacio público. En este ejemplo, podemos ver las imágenes de la Vía Julia, que era un descampado y que luego se transformó en una Avenida Bulevar.

Y en su opinión, ¿qué hace que un espacio público sea de calidad?

El espacio público tiene una virtud, que como he dicho antes, es lo que define más una ciudad. Yo creo que a los que nos interesa este tema, cuando vamos a cualquier ciudad por poco que tengamos un poco de tiempo,nos gusta pasear, y andar, y conocer, pues es lo más genuino,las ciudades o las culturas nuestras cada vez tienden (poco a poco)a homogeneizarse un poco a nivel de usos o de costumbres ciudadanas, todo mundo viaja mucho. Pero lo que define genuinamente cada ciudad o cada paisaje es su identidad.

Entonces el espacio público tiene que recoger este carácter del genius $\operatorname{loci}^{3}$ y dentro de un proyecto de espacio público es muy importante la sobriedad, tiene que ser realmente lo que decía Mies van

3.- La llamada al concepto de genius loci está muy presente en el discurso arquitectónico. Se refiere al trabajo fenomenológico de Norbert-Schulz (Norbert-Schulz, Christian 1980). Nota Ed. 


\section{on the w@terfront}

public art urban design civic participation urban regeneration

vol.61, nr2. May the 30th, 2019

ISBN: 1139-7365

DOI: https://doi.org/10.1344/waterfront2019.61.6.7
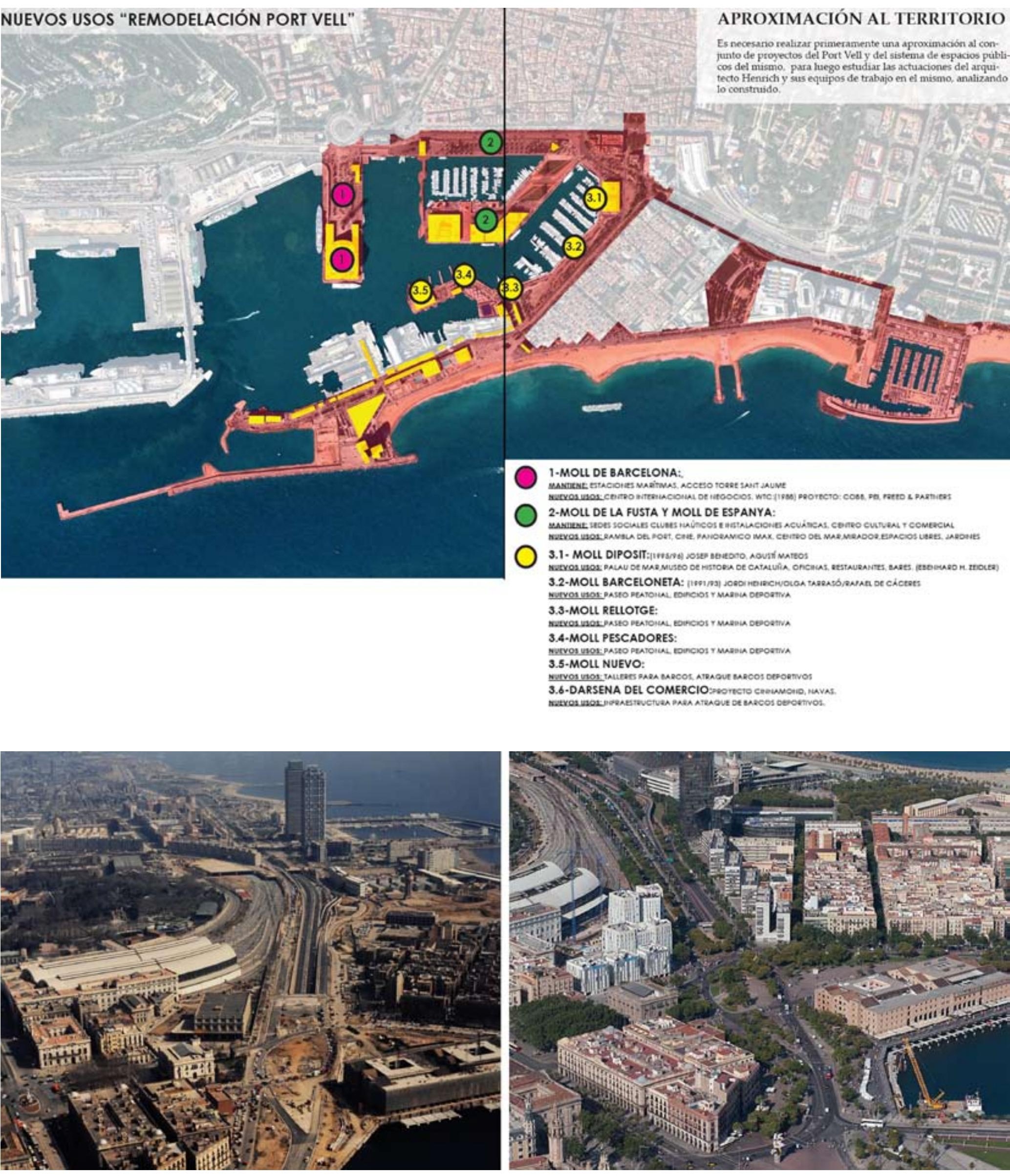

(C) Arxiu Administratiu de Barcelona 
der Rohe, que "menos es más", el espacio público tiene que estar construido con lo esencial, pero, al mismo tiempo, tiene que aportar identidad, es decir, tiene que poner en valor los elementos existentes, si los elementos existentes son anodinos o amorfos, en el espacio público tiene que crearse una propia identidad.

¿Y cuál es la idea? Es la creación de un espacio, ese espacio como decíamos es un proyecto arquitectónico, pero es también un proyecto espacial, la arquitectura es espacio, cuando pensamos en la estructura de un edificio tenemos que pensar, no en la estructura que sea, sino que esta estructura está creando un espacio, ese espacio puede ser una vivienda o un polideportivo, pero tiene que crear un espacio. Igual con el espacio público, la estructura del espacio público tiene que estar formada por elementos que creen espacios,espacios diáfanos y espacios continuos.

El espacio público sobre todo es un elemento de comunicación, de permeabilidad, de conexión entre diferentes espacios públicos o entre diferentes zonas urbanas, por tanto, tiene que establecer en todas sus posibilidades, la permeabilidad longitudinal, transversal, la conectividad, la accesibilidad, eliminar discontinuidades, crear modos -que si pueden ser rampas, que no sean escaleras- de permeabilidad y continuidad.

Y por otro lado, dentro de esta idea, sobre todo, la tendencia ya de hace muchos años, pero cada vez más, es la de reducir el espacio al vehículo para favorecer y ensanchar al máximo los espacios peatonales y para ciclistas.

\section{¿Para Ud. existe alguna diferencia entre urbanizar y arquitecturizar los espacios públicos?}

A ver, yo creo que esta es una pregunta como de creación de Proyecto Urbano. Proyecto Urbano, Masterplan, donde se crea una nueva Zona Urbana a partir de nuevos edificios, nuevas edificaciones y espacio público.

Mi opinión es que, y lo que intento hacer a veces en Concursos de Proyectos Urbanos, del Proyecto Urbano, de Masterplan, o Proyecto que puede ser de aquí del Puerto, es la de creación de usos urbanos, nuevas edificaciones que aporten mezcla de usos, si es posible que haya equipamientos públicos, pero, sobre todo, todo ellotiene que estar ligado con una estructura de espacios públicos de calidad.

Uno de los elementos que se ha desarrollado en Barcelona es la reactualización de las diferentes tipologías de espacios públicos: la calle peatonal, el paseo peatonalizado, el gran paseo donde hay circulación de vehículos (tipo Paseo de Gracia o la Diagonal), la plaza de barrio, la plaza central, el pequeño jardín, el parque de medidas medianas (como es en Barcelonaque se establecieron muchos parques en antiguas fábricas) y el gran parque.

Todo esto tiene que conformar una estructura de espacios públicos que, si puede ser, sea complementaria y cree una estructura de elementos de diferente dimensión y carácter que ayuden a crearuna estructura rica y,también, que aporte identidad. Y si por ejemplo, hay paisaje 


\section{on the w@terfront}

public art urban design civic participation urban regeneration
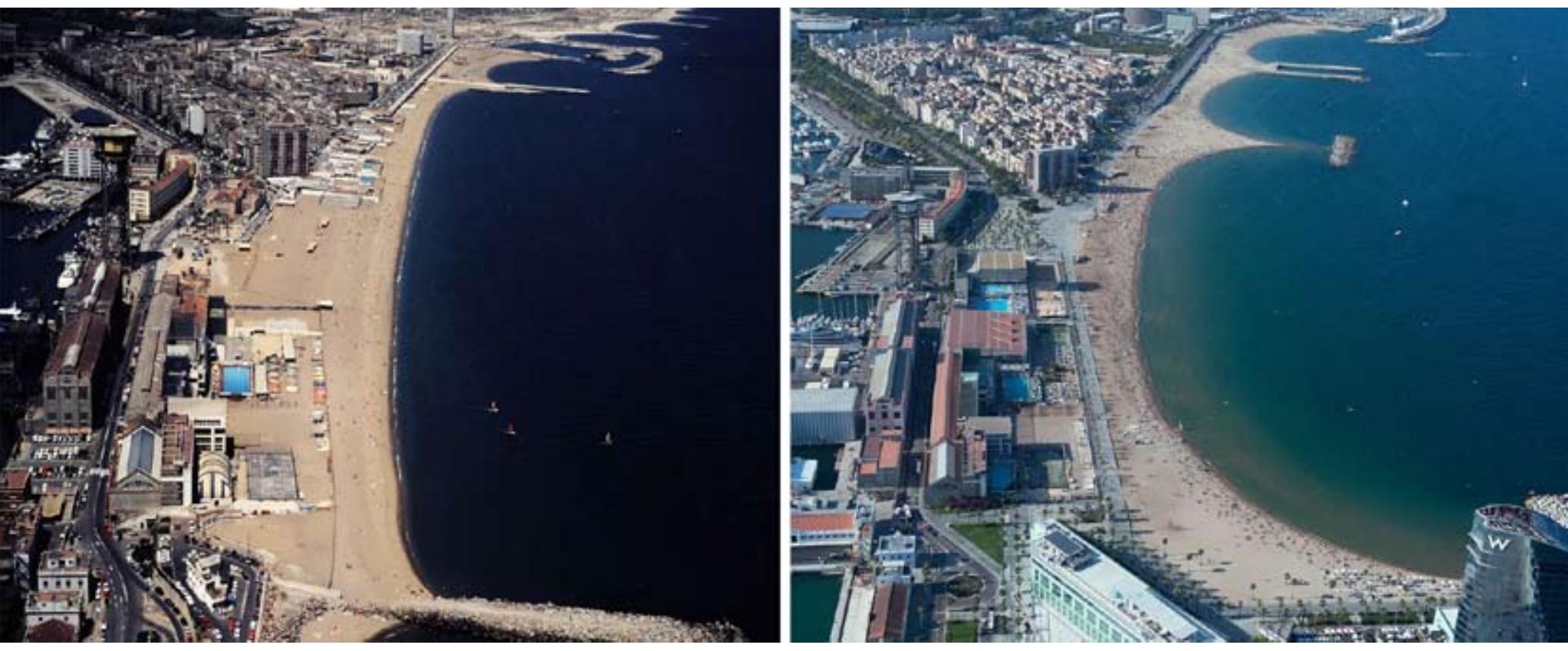

Antes y después del paseo de la Barceloneta (C) Arxiu Administratiu de Barcelona
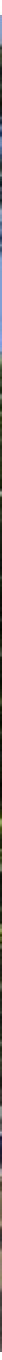

Farola Z Y Farola Kanya. Jordi Henrich y su equipo de trabajo.

8

(C) (i) Publicado por el POLIS RESEARCH CENTRE. Universitat de Barcelona 
o hay elementos de arquitectura de patrimonio, evidentemente hay que ponerlos en valor al máximo con los espacios públicos.

De hecho, lo que estoy diciendo es lo que ha hecho la ciudad desde la Edad Media, desde los griegos, el Ágora, dónde está el templo, los romanos, luego dónde se pone la Iglesia, dónde se pone el Palacio del noble, siempre hay una Plaza, es decir que en el fondo lo que estoy diciendo es que tenemos que aprender de la Ciudad Histórica ${ }^{4}$ que es muy sabia en general.

Las ciudades de Latinoamérica, de creación más reciente, tienen también seguro (es que conozco muy pocas), elementos históricos de sus inicios muy interesantes que hay que saber recoger, osea cada ciudad tiene su historia y cada ciudadtiene que saber recoger sus propias condiciones para luego darles forma contemporánea mediante un sistema común, no somos historicistas, no soy historicista, pero sí que tanto en espacio público como en arquitectura, como en paisaje, tenemos que aprender de los buenos ejemplos que existen desde tiempo inmemorial.

Un paisaje como los Jardines del Renacimiento en la Toscana nos enseña muchas cosas que hoy podemos aplicar, igual que los Parques de Le Nôtrede París o los Jardines Ingleses, todo esto lo podemos incorporar a nuestro bagaje de instrumentos para actuar en el espacio público o en el paisaje.

¿Y Ud. cree que Barcelona es la ciudad de los arquitectos, así como menciona Llatzer Moix?

Es una pregunta muy bonita, bueno Llatzer Moix ${ }^{5}$ es el periodista que escribe sobre los arquitectos de Barcelona. Supongo que hay muchas ciudades con arquitectos, tampoco quisiera yo aquí pensar, que Barcelona es la que tiene más arquitectos. Pero sí es una ciudad que evidentemente tiene una buena Escuela de Arquitectura, históricamente ha generado siempre buenos arquitectos, algunos buenos arquitectos, luego evidentemente hay muchos que seguramente no lo son tanto, verdad, pero hay una tendencia a generar, a buscar una calidad en la arquitectura, que está bastante generalizada.Pero yo creo que ha habido, bueno ahora no es un mal momento para la arquitectura, a pesar de la crisis, hay una calidad arquitectónica bastante generalizada.

Desde la finalización dela II Guerra Mundial hasta los años 1960, yo creo que en Europa, Estados Unidos, quizás Latinoamérica (lo poco que conozco) hubo una cierta buena arquitectura moderna, a raíz del Movimiento Moderno, luego en los años 1970, llegó el Brutalismo que empezó a empeorar las cosas, no sé qué pasó en las Escuelas de Arquitectura.Luego vino el Postmodern, que hizo que se hiciera mala arquitectura. Algunos países que dices, i¿cómo es posible?! , como en Francia, o en Inglaterra, fueron años bastante malos, Italia que había hecho muy bien después de la Guerra, había empeorado mucho.

Aquí en Barcelona, pues se sigue haciendo, yo creo que, una arquitectura correcta, siempre hablando de que es una parte no sé si mínima o no, pero que no es todo lo que se construye

4.- Henrich introduce aquí un concepto recurrente entre la profesión arquitectónica barcelonesa y que puede ser rastreado hastaDomènech i Montaner (Domènech i Montaner, Lluis 1878) y el G.A.T.C.P.A.C (GATCPAC 1931)Nota Ed. 5.- En referencia al libro "La Ciudad de los Arquitectos"(Moix, Llatzer 1994)Nota Ed. 


\section{on the w@terfront}

public art urban design civic participation urban regeneration

Barceloneta- Port Vell. Paseo Joan de Borbó

J. Henrich, Olga Tarrasó, R. de Cáceres, 1993

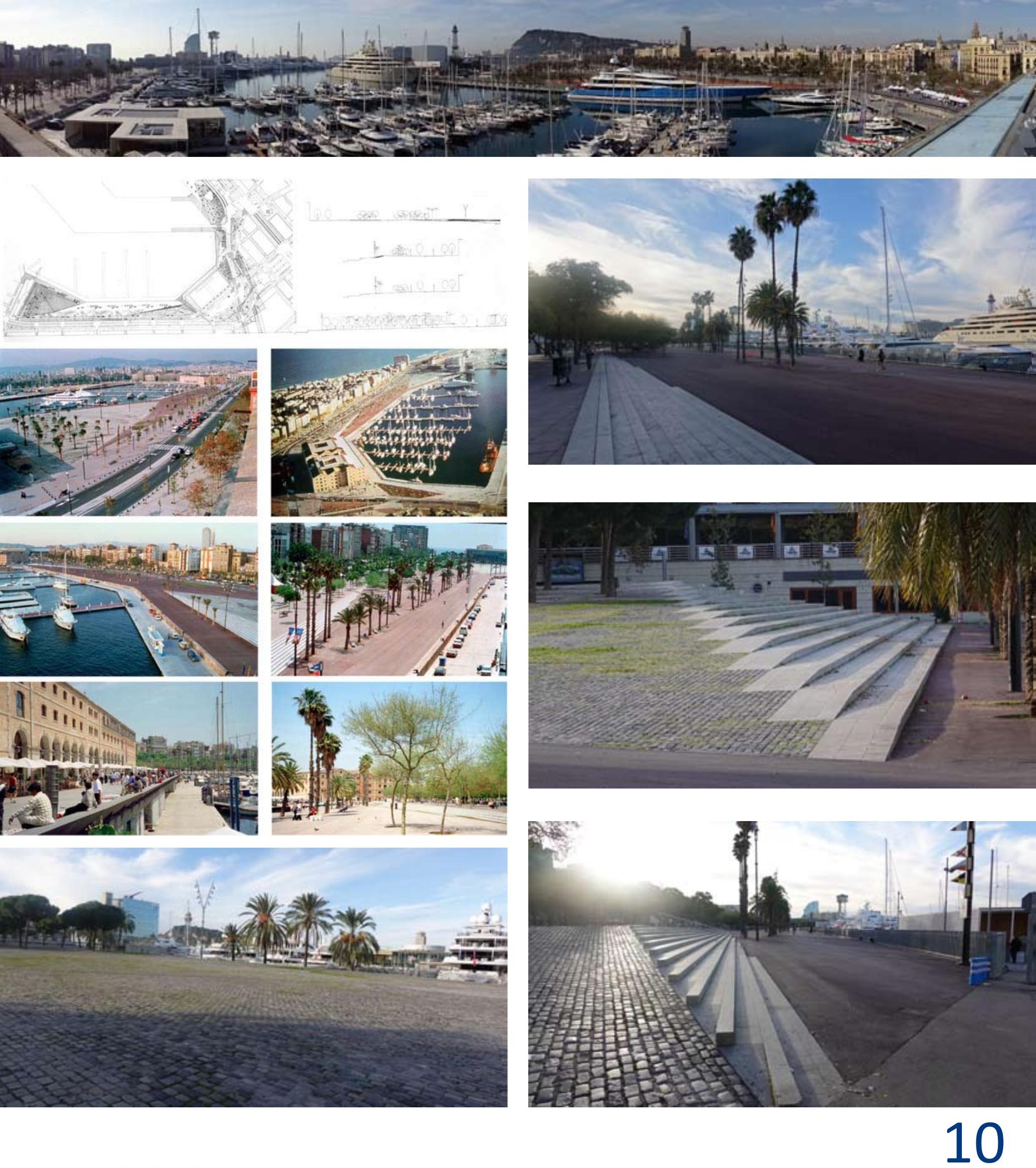

(c) (i) Publicado por el POLIS RESEARCH CENTRE. Universitat de Barcelona 
evidentemente, porque hay muchas cosas que no son buenas. $Y$ ahora, yo creo que es un momento en donde en general hay nivel, hay buena arquitectura, a nivel generalizado, algunos edificios demasiado icónicos, demasiado exagerados, pero sí que hay buenos arquitectos, como por ejemplo David Chipperfield, (por nombrar muy famosos) o el mismo BIG, tiene una raíz muy moderna, pero también es muy rico en expresiones que se salen de lo habitual, hay gente interesante haciendo cosas. OMA de Rem Koolhas, quizás Zaha Hadid podría haber seguido un buen camino, pero yo creo que se le fue la mano en el alarde curvilíneo, ha hecho cosas muy interesantes, pero se le ha ido un poco la mano, es el tema de la arquitectura estrella también, $^{6}$ Jean Nouvel, en un momento fue un gran revulsivo para Francia, porque Francia había tenido muy mala arquitectura.

En Barcelona, siempre ha habido pues una tendencia de hacer buena arquitectura y es una ciudad que busca la calidad. Sí tenemos que pensar que quizás no es generalizado, sobre todo cuando conoces un poco las ciudades francesas, pero por ejemplo cuando se hacen los Mercados, que se han renovado, se están renovando, ahora el Mercat de Sant Antoni, siempre se ha buscado que haya una buena arquitectura. Todo lo que es público en general se busca que haya una buena arquitectura. Más bueno, más malo, si podemos comentar caso por caso, pero sí que hay una búsqueda que las Instituciones promueven (y eso es lo más importante que te puede interesar), desde lo público se promueve que haya una buena arquitectura, en general.

Pero esto también va ligado a los espacios públicos, por ejemplo, hubo también o hay la tendencia, quizás ahora ya no tanto, del arquitecto estrella, cuando se planteó hacer el MACBA, pues se trajo a Richard Meier, y se hizo una Plaza en El Raval (que es un barrio que tiene problemas de degradación), se puso el Museo allí porque se hizo un Plan7 muy importante de la época inicial de Bohigas -que decíamos- se hicieron varios planes y éste era ligar la Ciudad Vieja, tal vez con un eje cultural y con la creación del MACBA, toda la zona del CCCB y todo esto. Ahí se encargó a Richard Meier, un arquitecto icónico y entonces el otro día me comentaban que bueno para controlar la luz que entra directamente en un Museo que tiene pinturas, es dificilísimo, es decir, el arquitecto icónico, extranjero, que es un modelo que se ha utilizado y se sigue utilizando en muchas ciudades, a veces da buenos resultados y a veces no.Porque evidentemente el Guggenheim de Bilbao es un hit que ha sido revulsivo para regenerar la ciudad, ahí acertaron mucho, un edificio que resuelve la situación de una ciudad bastante anodina que ha resucitado gracias al Guggenheim y a la gestión,por un lado, y por el otro el edificio. El MACBA no llegó a esto, y quizás, Richard Meier es un buen arquitecto, es un buen arquitecto icónico, yo he visitado algunos edificios, y bueno cuando las visitas dices bueno pues tengo mis reservas, sobre todo, no es el Guggenheim de Nueva York o el Guggenheim de Bilbao, no es muy hábil, tiene defectos.

\footnotetext{
6.- Sobre la arquitectura estrella en España puede consultarse “Arquitectura Milagrosa" (Moix, Llatzer 2010) Nota Ed. 7.- Se refiere al Ilamado Plan del Liceo al Seminario de Lluís Clotet i Óscar Tusquets que posteriormente se recogió en el PERI del Raval. "Potser el de major envergadura és l'avantprojecte de Lluís Clotet i Oscar Tusquets -recollit en el PERI del Raval- delsector "Del Liceu al Seminari», en el quals'ordena la forma de l'espaipúblicgeneratpelrosarid'edifici smonumentalsdesocupats i se suggereixen usos culturals i de lleurecol/lectius".(Bohigas, Oriol 1985, 53)Nota Ed.
} 
Pero los Ayuntamientos de aquí han dado siempre mucha importancia a los arquitectos, ¿ंverdad?

Sí, bueno, es lo que te comento, lo que se busca en general desde la Administración para todo tipo de proyectos, las Administraciones cuidan, por ejemplo,el Ayuntamiento de Barcelona o los diferentes Ayuntamientos Metropolitanos buscan en general una buena arquitectura.

\section{¿Quiénes influenciaron su manera de hacer ciudad?}

Bueno como te decía el Modelo Barcelona, que no sé si existe o es un modelo que ha ido evolucionando. Yo creo que hay una cosa también que es importante de Barcelona, a nivel positivo, estamos hablando desde el año 1978, pues han pasado 40 años desde el inicio del Ayuntamiento democrático, que son muchos, y hablando de Barcelona y de su entorno inmediato, la influencia del espacio público y de la creación del espacio público, sigue digamos generando nuevos proyectos, nuevas formas, es decir, a pesar de que se han hecho muchas cosas, quedan cosas por hacer, eso por un lado, y por otro lado, se van haciendo, que no todo lo que se hace es acertado, evidentemente hay errores, que hay cosas que se podían haber hecho y no se han hecho, evidentemente hay cosas que no se han hecho todavía, pero se siguen haciendo cosas, se van peatonalizando, por ejemplo, ahora recientemente las cosas que van evolucionando, Travessera de Gracia los sábados, se corta y es peatonal, este tema de la peatonalización está presente y va avanzando, no podemos pensar que las cosas ya están resueltas, porque no lo están.

Ahora se está resolviendo la Plaza de las Glorias ${ }^{8}$, que ya lleva unos cuantos años y esperamos que algún día se acabe, parece que la cosa está más o menos que puede llegar a acabarse, digamos que ahí se hizo un error, se hizo un anillo elevado que no llevaba a ningún sitio, ahí se hizo un error. Es decir que no todo se acierta, ni hay un único modelo, entonces, ¿qué es lo que yo intento aprender y aplicar?, o ¿qué es lo que yo he aprendido?, es lo que te decía, aprendiendo de todo lo que está bien, intentando mirar con ojo atento donde voy, aprender y aplicarlo luego a lo que pueda yo ir proyectando.

Entonces la base de todo esto, como te decía, es por un lado la sobriedad, el proyecto de espacio público que esté integrado en su contexto, y por otro lado aportar una identidad a nivel contemporáneo con mucha sobriedad, poner en valor el lugar, incluso crear un espacio.

\section{Ud. siempre trabaja en equipo, ¿quiénes conforman su equipo?, ¿cómo forman los equipos?}

Sí, bueno, sobre todo lo que hacemos en equipos son concursos diferentes. Y entonces depende del concurso tenemos un equipo, que hacemos por ejemplo Concursos de Integración Puertos y Ciudad, que llevamos como 4 concursos, vamos probando, tenemos esta especialidad digamos,

8.- La plaza de Les Glòrieses una de las asignaturas pendientes en la urbanización de Barcelona desde que Cerdà, en 1859, planteara este espacio y Jaussely en 1903 lo ensalzara a nuevo centro cívico. En los años 1960 se reestructuró como un nudo viario urbano. Posteriormente en 1992, se inauguró una nueva remodelación a cargo de A.Arriola, A. Monclús y X. Ruiwamba. Sin embargo esta solución, un tambor elevado para gestionar la relación entre la Gran Vía y la salida por la autopista de Mataró, siempre fue custionada y por ello se lanzó un concurso internacional para su remoldeación que, en 2014, ganó la UTE Agence Ter \& Ana Coello de Llobet, con el lema Canopia Urbana. Hoy en día la plaza está en remodelación.Nota Ed. 
desde el trabajo que he tenido la suerte de hacer en el Puerto de Barcelona, pues vamos haciendo este trabajo.

Luego hacemos alguna cosa de Paseos Marítimos en Italia, con unos arquitectos italianos, es decir, he hecho cosas en Rusia con unos arquitectos rusos, también en Francia con un urbanista francés, es decir que el tema de Internet nos ayuda mucho a comunicarnos y a compartir el trabajo, como es obvio y evidente. Y esto permite crear alianzas así estratégicas con gente diferente que es muy interesante.

A veces no es fácil, porque los concursos sabemos cómo son, pero bueno, vamos haciendo cosas diferentes, siempre aplicando el tema de espacio público como elemento motor de cualquier intervención.

Las intervenciones que ha realizado en la ciudad de Barcelona, ¿comparten similitudes entre ellas?

Hay dos o tres temas muy importantes, esenciales en el Proyecto, uno es, este de minimizar el impacto de las secciones vehiculares y de los movimientos vehiculares, simplificarlos al máximo, es decir si una calle puede tener un carril en lugar de dos, si hay un cruce que hay que simplificarlo pues se simplifica, es decir, que el espacio vehicular sea mínimo para favorecer siempre los recorridos, la permeabilidad, la continuidad, los recorridos peatonales y la máxima amplitud.

Esto quiere decir que se genera un plano de suelo, un trazado que es muy importante, este trazado al mismo tiempo que piensas o que resuelves el tema de la movilidad, que no es tan obvio a veces (de peatonalizar al máximo lo que puedas), va ligado también ya a una forma de ese espacio, de este plano del suelo que viene dado por dos temas importantísimos, uno es la micro topografía, tratamiento topográfico de cada lugar, que tiene que estar relacionado con cada lugar, sus pendientes transversales, longitudinales, para que las aguas corran, el espacio público evidentemente nunca es horizontal y por tanto su misión física número uno es recoger las aguas y conducirlas para que se vayan al sistema de alcantarillado, de saneamiento. Esto tan banal, esto da forma al espacio público, y esta forma de espacio público está ligada a su contexto. Lo que digo puede parecer muy obvio, pero hay gente que no lo hace así y se olvida de esta forma topográfica del espacio público y le salen cosas ajenas. Entonces este trabajo arquitectónico y de trazado, de micro topografía, trazado viario, minimizando el impacto del vehículo y creación de superficies peatonales (que normalmente son pavimentadas), es el tema principal inicial.

Y luego este plano del suelo, que no es horizontal, que tiene movimientos topográficos que depende del lugar, puede ser horizontal si está delante de un Muelle o a lo largo de una playa, pero debe tener pendientes transversales evidentemente, o puede tener un pequeña sistema de pendientes porque tiene una calle aquí y otra aquí, y pues tiene que tener una rampa o escaleras, entonces cuando salen estas cosas,siempre buscar recrear y poner en valor los elementos topográficos, y si se pueden crear digamos unas gradas, unas escaleras combinadas con rampas, etcétera., que recrean la riqueza de elementos de creación de espacio público, que favorezcan la creación de un lugar. 


\section{on the w@terfront}

public art urban design civic participation urban regeneration

vol.61, nr2. May the 30th, 2019

ISBN: 1139-7365

DOI: https://doi.org/10.1344/waterfront2019.61.6.7

Barceloneta- Port Vell. Plaza del Mar y Paseo de la Barceloneta

J. Henrich, Olga Tarrasó, J. Artigues, M. Roig, A.M. Cstañeda, C. Fuente 1995, 2001

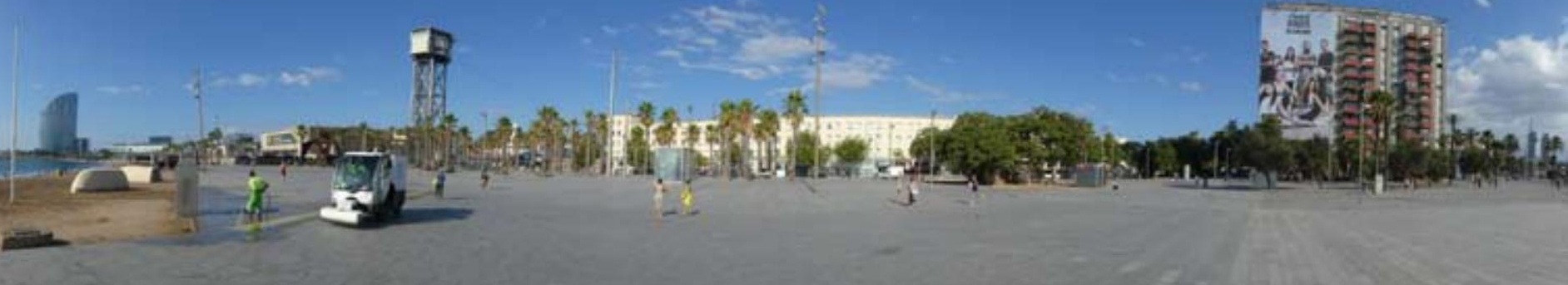
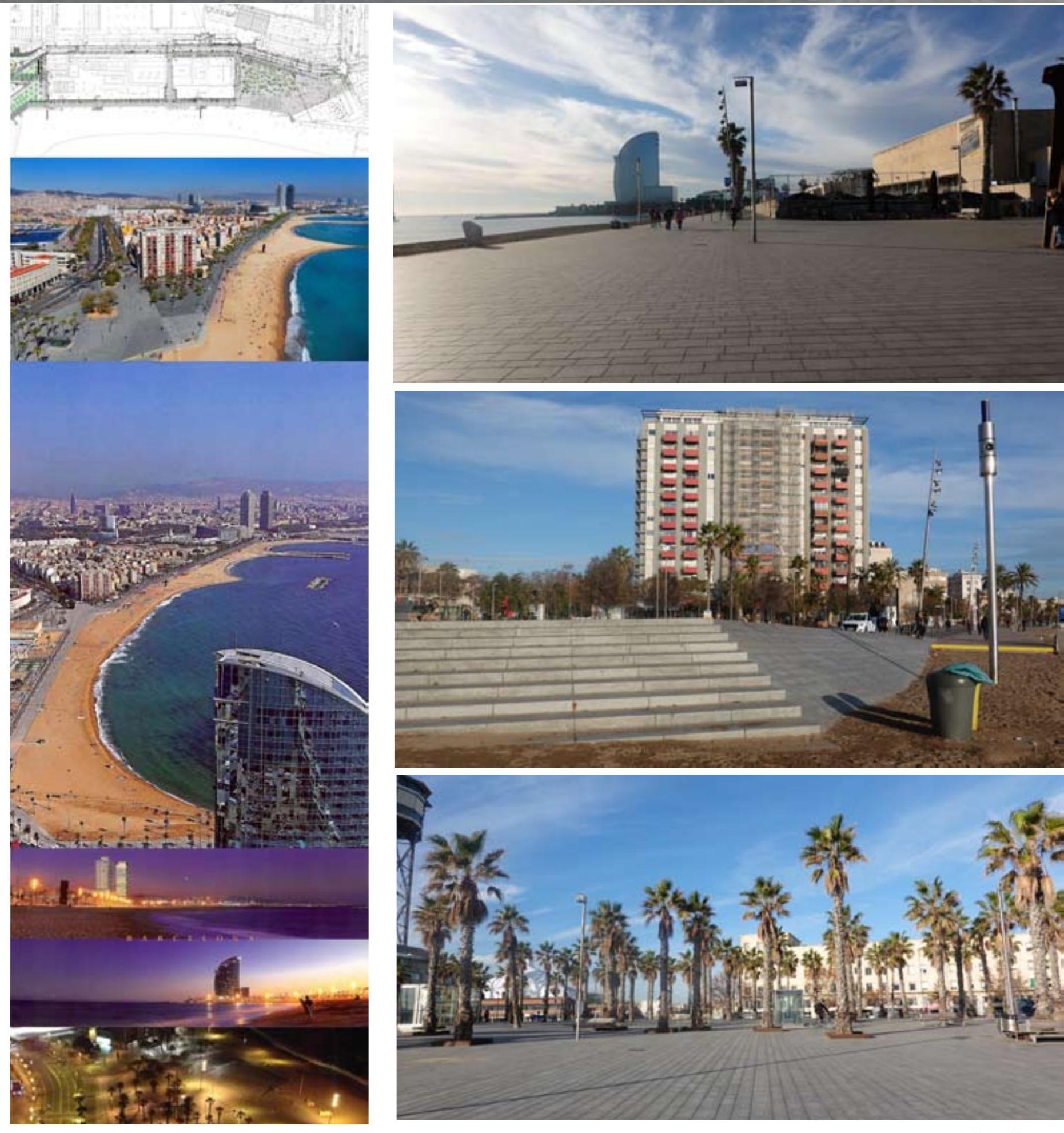

(c) (1) 


\section{on the w@terfront}

public art urban design civic participation urban regeneration

Barceloneta- Port Vell. Plaza del Mar y Paseo de la Barceloneta

J. Henrich, Olga Tarrasó, J. Artigues, M. Roig, A.M. Cstañeda, C. Fuente 1995, 2001
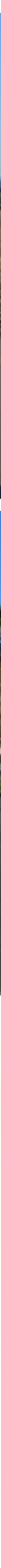

(c) (1) 
Y este plano del suelo, luego se completa con la estructura vertical, la estructura vertical de los elementos inherentes, que son el arbolado entendido como estructura, como elementos vivos, pero como estructura, es decir, el arbolado proporcionado a las dimensiones del lugar, por su altura, por sus ritmos, creando espacios o creando ámbitos de paseo enmarcando o filtrando la arquitectura y los elementos de iluminación. Luego está el tema del mobiliario que complementa estos elementos principales.

Con respecto al arbolado, ¿a los barceloneses no les gustan tanto las palmeras verdad?

A ver, las palmeras ${ }^{9}$ se han utilizado, yo no sé cuál es el origen de la palmera en Barcelona o en la costa catalana, pero hace muchos años que existe. Ya en las casas de los indianos (que son los que fueron a América y volvieron), ya se plantaban palmeras hace más de 100 años, osea no es un elemento de creación reciente. Sí que tiene una virtud,la palmera cuando la plantas, aunque sea bajita, ya es un árbol ancho que tiene una presencia importante. No hace mucha sombra, pero da una estructura complementaria, yo creo que más que otros árboles. Ahora, aquí y en todo el Mediterráneo, hay el problema del picudo, que mata a la palmera, todavía no hay solución, la que resiste mejor es la palmera washingtonia.

Entonces, ¿̇lo principal es el diseño del suelo? ¿'En sus intervenciones en el espacio público intervienen en fachadas? ¿Tienen algún criterio para que el privado intervenga o hacen lo que pueden con lo que existe?

Lo principal es la estructura del espacio. A ver es una pregunta muy interesante, bueno en general el Proyecto de Espacio Público es un proyecto en general en zonas urbanas ya consolidadas donde no intervenimos en las fachadas. En algunos casos, se da la posibilidad de alguna intervención, pero es como complementario. Es un tema más accidentado.

¿Cuál es el criterio que tienen para diferenciar espacios públicos, dotarles de alguna singularidad o volver un espacio icónico?

Bueno lo que te decía es, a ver, hay como dos posibilidades, una es tener la suerte de hacer un espacio público a lo largo de un río, delante de un canal, delante de un lago, delante del mar o delante del Puerto que lo que tienes que hacer es poner en valor por un lado el paisaje, pero por otro lado la ciudad que da a este paisaje, por lo tantoel espacio público es un elemento que tiene que conectar estas dos escalas y por tanto es un espacio que también al mismo tiempo tiene las dos escalas, por ejemplo el Paseo de la Barceloneta, el Muelle de la Barceloneta, el Paseo Marítimo, por un lado estás relacionando con el Barrio de la Barceloneta, son parte del barrio de la Barceloneta y por otro lado tienen que estar abiertos al paisaje, al Puerto, al paisaje del Puerto o al paisaje del mar y la playa. Y por tanto,tiene que tener esta idea de doble escala

9.- En Barcelona existen varias palmeras centenarias ubicadas en antiguas fincas privadas o en edificios colectivos (Catedral, Casa de l'Ardiaca). Algunas de ellas han pasado a estar situadas en el espacio público, como la famosa de la Plaça de la Palmera que secciona en dos el arco de la obra de Richard Serra "Mur". Como elemento de urbanización las palmeras están presentes desde el momento de la creación del Paseo de Colon con motivo de la Exposición Internacional de Barcelona de 1888. Entre 1997 y 2017 no se plantaron palmeras en los proyectos urbanos barceloneses (Nota del Ed.) 
también longitudinal, es decir,que no se conforma con una escala pequeñita de barrio sino que al mismo tiempo tiene que abrirse a las vistas transversales o diagonales hacia el paisaje, pero también crear una secuencia espacial que cree una escala apropiada que es la escala del lugar y el carácter del lugar.

El Muelle de la Barceloneta no es un jardín, no es un prado, es un antiguo Muelle que nunca había sido un Muelle público, nunca había existido ese espacio público, por tanto, no estamos recuperando nada que existiera, estamos creando uno nuevo, pero por otro lado tenemos que crear un espacio que mantenga las condiciones inherentes a un Muelle, que es un ejemplo de pavimento duro, no es un prado.

Un proyecto grande que hice y que me hizo pensar mucho fue el del Arco del Triunfo, el PasseigLluis Companys, que antiguamente había tenido un paseo debajo del Arco del Triunfo donde pasaban los coches, desde 1888 cuando se creó, con unos paseos arbolados laterales, luego se hizo un aparcamiento en los años 1960-1970 y se rompió todo esto y se crearon unos grandes parterres de hierba en medio que rompieron la posibilidad de pasear por debajo del Arco del Triunfo que se aisló con una rotonda de prado, como es un buen momento le ponemos césped, claro esto rompió completamente el espacio público.

Entonces el trabajo fue reconstruir la idea original sin que pasaran coches por debajo del Arco del Triunfo sino que pasaran las personas y esta recuperación transformando el paseo original en uno nuevo totalmente peatonal, pues ya me ayudó a ver que hay que mantener unas ciertas condiciones de lo que pasó en el lugar,que el césped no lo resuelve todo y de que a veces se habla mal de las plazas duras; la plaza más bonita del mundo que es la Piazza de San Marcos es dura y es maravillosa.

Entonces bueno, es poner en valor los elementos de paisaje o de patrimonio, como es el Arco del Triunfo o el Palacio de Justicia, que también está enel paseo este del Arco del Triunfo, tiene un orden con relación al espacio transversal, está centrado con respecto al Palacio de Justicia, hay una escultura contemporánea al costado, es decir hay una relación con el contexto de valor, sea paisaje o sea patrimonio.

Luego está el espacio público en un sitio que no tiene nada, que es anodino, anodino en el sentido que no tiene valores intrínsecos, pero siempre hay un valor, que es la creación de un lugar, la creación de un lugar donde no existe.Por ejemplo la Rambla de Gavá, o la Rambla del Poblenou que está hecha en una calle estrecha en un barrio de edificios normales, no tiene un valor, ¿y qué es lo que le da valor?, su propia esencia, el crear un paseo peatonal, el reducir o eliminar los coches, el que puedas crear un espacio de fachada a fachada en los 20 metros, en que esta Rambla llegue hasta el mar, por ejemplo, esto es extraordinario, no llegaba hasta el mar como Rambla, luego al final esto se acabó haciendo y cruza la Gran Vía y llega hasta el parque de El Clot, por ejemplo, es un eje. 


\section{on the w@terfront}

public art urban design civic participation urban regeneration

ISBN: 1139-7365

DOI: https://doi.org/10.1344/waterfront2019.61.6.7

Rambla Brasil, 1997. Carrer Badal, 2001. Gran Vía Carles III, 2002

J. Henrich, Olga Tarrasó
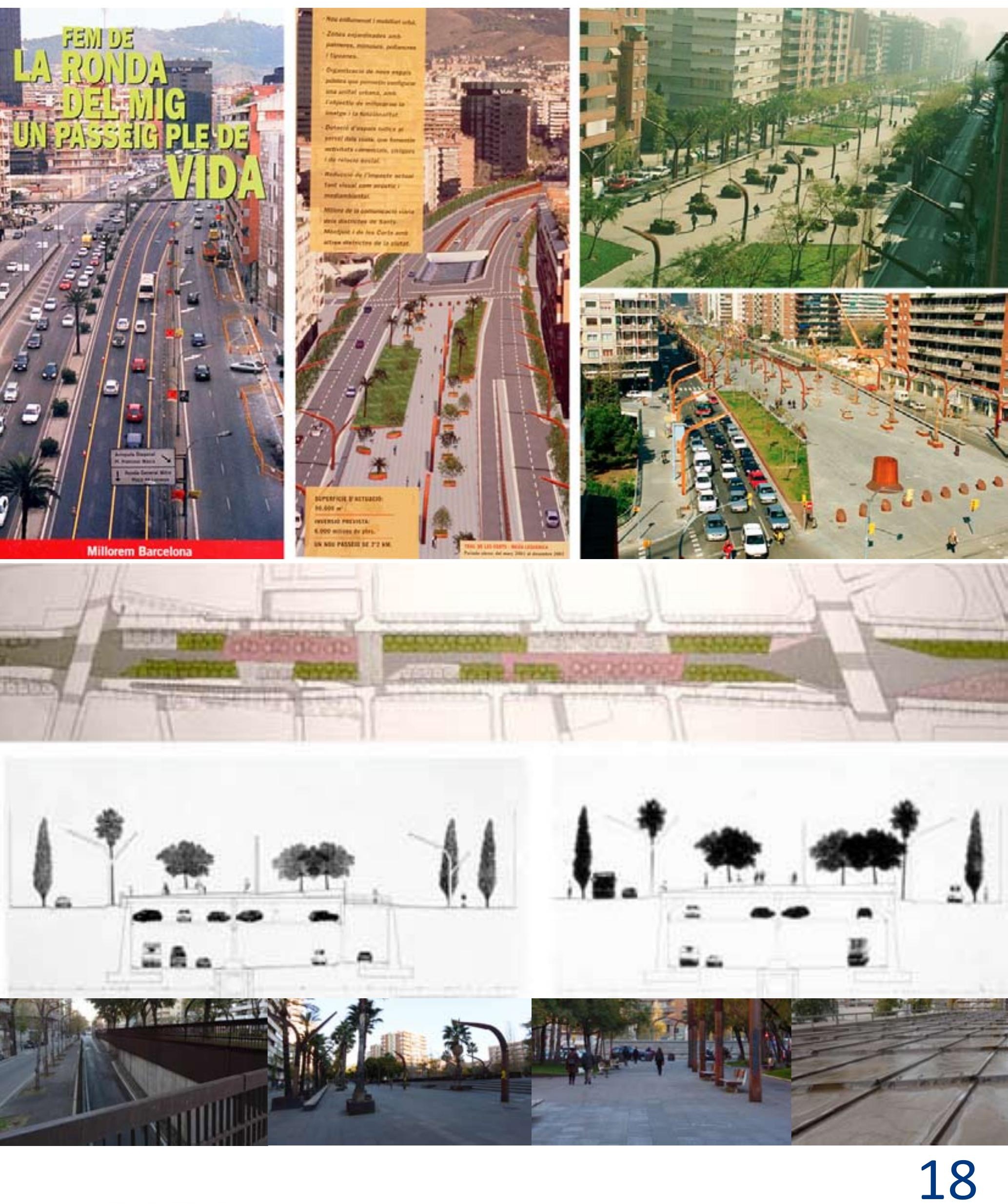

(c) (1) 
Y la Rambla de Gavá igual, se quitan los coches, se hizo totalmente peatonal, es una rambla comercial de una ciudad pequeña pero histórica que estaba muy mal y la resolución fue hacer una rambla peatonal de fachada a fachada, quitar los coches, los coches van por la calle de al lado, los coches que aparcaban se ponen en un aparcamiento subterráneo, -esto es otro de los elementos que preguntas más adelante-, los aparcamientos subterráneos son muy importantes para resolver el tema de los aparcamientos -evidentemente- y que aquí se hace muy bien en Barcelona, no así en otras ciudades.En donde no hay, en general, atributos, siempre los hay al crear un espacio que dé nuevas conexiones, nuevas posibilidades de relación entre las personas, de usos diferentes, porque el espacio público tiene que ser abierto a todos los usos cívicos.

En su opinión, ¿̇un espacio público calidad es el escenario del vitalismo urbano, del conflicto, o es un espacio que debe ser controlado y vigilado constantemente?

Creo queesto forma parte más de la evolución social de cada barrio, de cada ciudad, de cada ámbito urbano. Creo que hay ejemplos que nos ayudan un poco, si tú vas a la Plaza de Rius i Taulet de Gracia, no sé si hay conflicto, vas por la tarde, te tomas una cerveza, y es un sitio espléndido que ha existido toda la vida, ahora que hay menos coches que cuando yo era pequeño. Si vas a la Rambladel Raval ${ }^{10}$, que es un espacio también magnífico, que se creó nuevo digamos, vaciando tres manzanas para crear un espacio que no existía, pero que tiene esta vocación como la plaza de Gracia, pero que tiene más vocación de paseo, porque es más alargada, tiene más dimensión, ahí puede haber conflicto, yo creo que en la Rambla del Raval se ha hecho todo lo posible desde el Urbanismo y desde el Espacio Público para regenerar el barrio, se ha puesto la Filmoteca, hay edificios nuevos de oficinas y viviendas, y en el Raval últimamente vuelve a haber conflicto, porque el tema social evoluciona,es un tema ligado y aquí entraríamos un poco al tema del inmobiliario, que es quizás el tema más negativo que puede haber en estos momentos en Barcelona, porque genera todo tipo de problemas, desde expulsión de gente que ha vivido toda la vida en un sitio, a la compra de muchos pisos por bancos y grupos de inversores, estos buitres que vacían pisos que son ocupados por narcotraficantes (no soy experto del tema), y ahora el problema es eso, es un problema que va evolucionando.

Evidentemente las ciudades tienen zonas conflictivas, creo que Barcelona en general es una ciudad segura, en general, creo que todo el mundo, los que vivís aquí hace tiempo, lo habéis visto, y digamos que esto es fruto del cierto equilibrio social. Evidentemente Barcelona está muy bien, no es como Dinamarca, estamos en un país muy difícil como es España, (que esperemos que un día de estos dejemos de ser españoles), esto entre paréntesis, porque es un país que no resuelve el temainmobiliario, uno de los problemas que tenemos que no se resuelve en Barcelona porque dicen que es un problema estatal -que no lo sé-, y que aún no se ha resuelto, es el tema de dotar a la ciudad de vivienda pública a precio asequible como tienen otras ciudades como Berlín, Viena, o un sistema controlado. Esto creo que es lo que puede generar más conflicto en este momento. Es el dominio de las clases digamos inversoras o del mundo inversor, de las 
clases rentistas sobre el parque inmobiliario. Esto es lo que quizás puede generar más conflicto, más desahucios y la cosa más preocupante es que no se resuelve. Es algo muycuriosodado que Barcelona ha tenido desde el año 1978 gobiernos de izquierdas en general, los socialistas digamos que hacían cosas bien hechas, ahora también a nivel municipal siguen haciendo evidentemente, hubo un paréntesis 2011-2015 de gobierno de derechas y ahora vuelve a ser de izquierdas, pero no sé muy bien si hacen cosas pero prometieron muchas viviendas públicas.

La parte más de derecha de convergencia se ve que no hicieron tanto, bueno no soy experto, pero lo que más me preocupa es que en todos estos años de gobierno socialista, este problema de la vivienda ha existido siempre, tanto en Cataluña como en Barcelona, con sus crisis, sus idas para abajo, con sus burbujas. Barcelona antes de las Olimpiadas era una ciudad barata para vivir comparada con los sueldos, con las Olimpiadas ya se empieza a encarecer, luego se paró, baja un poco, vuelve a encarecerse, supongo que ha pasado con todas las ciudades que no están decadentes, supongo que es así, pero lo que hace falta aquí en relación con otras ciudades europeas es esto,un control desde lo público, de una creación de vivienda pública, se habla, se hace, se crea, pero siempre en pequeñas dosis.

En su opinión, ¿qué tan importantes son los espacios públicos como espacios vivos en una sociedad democrática, en un momento histórico donde la comunicación digital y la mercantilización del espacio público están aumentando?

Es lo que más o menos ya te he dicho, el espacio público es esencial.Lo último que he hecho es esta Plaza Ramón Berenguer (2015) ${ }^{11}$, delante de la Muralla, donde delante había un jardín, había un rincón donde se ponían unas cuantas personas a dormir, lo que hicimos fue abrirlo, poner la plaza a nivel superior, a nivel urbano, poner en valor el nivel de la cota antigua romana, eliminar el jardín y hacer una plaza dura con árboles y vegetación pero con gradas, este sistema arquitectónico pone en valor la Muralla reconstruida con la Capilla de Santa Agatha que es tan bonita y crear un recorrido a lo largo de la Muralla que se va completar con otra plaza más abajo de otro arquitecto.

Ahora ahí van los skaters, hay las terrazas, las gradas las ocupan los que van al Spritz, a tomarse el Spritz, y dices, bueno qué mejor se puede hacer, antes había un paso así pequeño que con los turistas tenías que hacer cola, ahora se ha ampliado al máximo lo que es la calle, se ha creado un recorrido, se ha puesto en valor un elemento urbano como es la Muralla, se ha conectado con la Vía Laietana y se ha creado una pequeña ágora. Y esto es todo positivo. Y esto es un poco yo creo lo mejor del espacio público, que automáticamente está usado correctamente, y es uno de los valores de Barcelona.

11.- Como consecuencia de la formulación de Cerdà (1860) de tres vías (A,B,C) que perforaban la ciudad antigua, a partir de 1908 se ejecutan las obras de la Vía Laietana(Vía C) derrocándose varios centenares de edificios. El segundo tramo de las obras siguió el trazado de Puig i Cadafalch dejando a la vista un gran paño de la muralla romana y los edificios góticos de la Plaza del Rey, lo que dio motivo para la creación de la marca "Barrio Gótico". Para potenciar la vista de esta zona se reservó un espacio para plaza que sería urbanizó por Adolf Florensa en la década de 1950 con diseño de jardín de Rubió i Tudurí..Véase(Florensa, Adolf 1958; Tatjer, Mercè 2000; El Haddad, Marie 2017; Ríos Díaz, Marien 2017; Fuster, J- Nicolau, A-Venteo, D 2001). Nota del Editor 
Por ejemplo ahora, hicimos una proyectoen un Concurso en París (que teníamos que haber ganado pero no ganamos), que era un tramo de los Campos Elíseos que va desde el periférico de París hacia Le Defense, al Oeste, pues era como la Diagonal o como la Gran Vía, con dos paseos laterales con plátanos y unas aceras muy estrechas, la parte central es una carretera nacional, entonces es un tema burocrático, pero estos paseos laterales que originalmente eran para ir a caballo y esas cosas, ahora estaban llenas de coches aparcados.En Barcelona en la Diagonal, hay que arreglarla, si tenemos lo que se ha hecho, se ha hecho muy bien y la parte antigua no está bien, pero la parte antigua yo no recuerdo que nunca haya habido coches, ¿Qué quiero decir con esto? Será el clima, será que a la gente le gusta pasear, en Barcelona cuando se hace un espacio público nuevo, la gente va a ocuparlo, se ocupa, y hay un cierto orden, si te fijas hay mucho tráfico, -que esto tendría que disminuir-, pero no hay un excesivo desorden en el tráfico, no hay coches aparcados encima de la acera, en general vemos que hay una tendencia yo creo en general bastante ordenada.

Esto quiere decir que en este período que te decía de 2011-2015 que mandó la derecha catalanista digamos, la derecha que por su tradición no sabían muy bien si existía o no el espacio público, pero siguieron haciendo espacio público, es decir, el Paseo de Sant Joan ${ }^{12}$ empezaron los socialistas, pero ellos no dijeron que no lo harían, sino que lo continuaron, supongo que, por compromiso cívico, no conozco la historia, pero hicieron la segunda fase.

Tiraron el anillo de las Glorias, que hicieron los socialistas y no lo quisieron tirar porque costaba mucho, y ellos como no lo habían hecho, pues lo tiraron, porque había una demanda vecinal, que el anillo había que tirarlo, y bueno lo tiraron, algunos arquitectos dudaban, de dejar un trozo, hacer un paseo superior que la verdad no servía para nada, todo era negativo, había que tirarlo.

Lo hicieron estos de derecha, acabaron el Paseo de Gracia, los laterales estaban mal, estaban antiguos, todavía con ventilaciones elevadas, luego lo acabaron de una manera elegante, ha quedado un lateral elegante, ha quedado todo perfectamente.También hicieron la Diagonal, la Diagonal los socialistas no la habían hecho, cla Diagonal cómo se hizo?, se hizo porque los comerciantes lopidieron, es un paseo precioso, más bonito casi que el Paseo de Gracia. Además, ahora es como un eje en ángulo. El proyecto está hecho hasta el Paseo San Juan, que no lo hacen ahora, no sé por qué. Pero bueno, que la Diagonal lo pidieron los comerciantes, bueno es que la ciudad tiene comercios, pero no es un centro comercial, esta es la diferencia, entonces se hace un espacio público y si quieres miras las tiendas y si no, estás en un espacio público, que es público. Y ellos a partir de las demandas de los comerciantes, hicieron la Diagonal, la hizo una amiga, que está en el Ayuntamiento, que le fue muy bien, como el espacio público de Barcelona, muy sobrio, sencillo, ampliaron las aceras hasta los árboles, esto que es tan obvio, no es tan inmediato en otras ciudades. Tenemos un problema con el tranvía, bueno yo soy un anti tranvía, porque se puede cargar la Diagonal, la ha podido romper, hay que buscar un equilibrio, se hizo la Diagonal. ¿Que lo hicieron porque pidieron los comerciantes de la zona rica de Barcelona? Sí, 12.- Primera Fase: Proyecto de J.Graells 1999. Segunda y Tercerca fase: Proyecto de Lola Domènech, 2012-2015. Nota del Editor 
pero es para todos. Y esto quiere decir que la fuerza del espacio público hace que a través de los diferentes gobiernos municipales se vaya actuando en el espacio público.

De aquí ahora como pequeño comentario que es lo de la integración de las infraestructuras urbanas a través del espacio público (que es el tema de los aparcamientos si quieres lo hablamos luego).

Sobre el Proyecto del Port Vell, ¿qué tuvo en cuenta para el Proyecto de Espacio Público: el tejido existente (lo físico y lo social), la materialidad (materiales nobles, resistentes, con bajo costo de mantenimiento), elementos urbanos (mobiliario de diseño de autor iniciales/ actuales), obras de arte público, espacios flexibles o espacios destinados a ciertas funciones?

El Port Vell en el que,digamos, a lo largo unos 30 años, he tenido la suerte de trabajar, muchos de ellos en colaboración con Olga Tarrasó, y luego ya con otros equipos, es una suma de diferentes proyectos, osea no es un único proyecto, esto es también muy importante, en la explicación de cómo son las cosas, no es un único proyecto hecho de golpe sino que es una suma, sí que hubo al inicio antes de empezar a construir el primer proyecto, un primer dibujo de espacios públicos del perímetro de la Barceloneta que era sobre todo el Muelle de la Barceloneta, que fue el primero que se construyó y luego el Paseo Marítimo Primera Fase que es el que da al barrio de la Barceloneta y, luego, hicimos en este primer plano que es un dibujo, una maquetala hicimos parala primera aproximación al Parque de la Barceloneta, al Paseo Marítimo delante del Hospital del Mar hacia la Villa Olímpica.

A partir de este primer proyecto que fue el Moll de la Barceloneta, que se hizo en colaboración con el Puerto. El Puerto ya había iniciado antes el Moll de la Fusta ${ }^{13}$, la primera versión del Moll de la Fusta que es del año 1987 creo, el Moll de la Barceloneta es del 1992-1993, se acabó para las Olimpiadas casi todo, quedó algún tramo que se acabó en el 1993, pero se inauguró para las Olimpiadas-lo pagó el Puerto y el Ayuntamiento hizo el proyecto en colaboración con los técnicos del Puerto. De esta primera relación pues yo he ido continuando a través de los años y a través de diferente gente del Puerto, y ahora estamos haciendo esta última fase que es al Sur del Hotel W, la Marina Vela, que se integra a través de los espacios públicos, la marina deportiva, la última fase, claro, son diferentes proyectos, cada uno es muy diferente del contexto y de relación tanto con la ciudad como con el ámbito digamos paisajístico, osea del Puerto-

Los elementos comunes son los que hemos comentado al principio, por un lado, cada proyecto responde a sus condiciones, tanto funcionales como si es necesario tráfico o no, en el Moll de la Barceloneta era necesario el tráfico, en el Paseo Marítimo afortunadamente no, esto ya genera una diferencia muy grande pero lo que los une es esta idea de crear -como te decía- esta doble escala, de espacios ligados al barrio pero por otro lado, espacios a escala de ciudad, que crean un gran paseo en el sentido longitudinal y en el sentido transversal se busca que sea lo más amplio posible y luego que se abra poco a poco a nivel de vistas y de pendientes, de micro topografía, de 
creación de espacios de estancia como las escaleras o las gradas, todo esto, si se puede crear esta micro topografía donde fuimos el otro día que subimos, donde puedes apreciar mejor las vistas y creas unas gradas, una gran plaza donde se ponen actividades como las ferias, la fiesta mayor, un circo.

Cada espacio es diferente, el Paseo Marítimo es un sistema de plazas para el barrio que están unidas y crean esta doble escala de paseo urbano abierto a la playa, incorpora la playa como espacio público, iluminándola de noche, que esto no existía, no es un espacio negro a la noche sino que está iluminado, luego creo que lo cierran a la noche porque tiene demasiado éxito (entre risas), pero esto ya no lo sé, pero ayuda a crear esta imagen de la playa nocturna, el espacio público es esencial que esté iluminado.Incluso en los calendarios turísticos de las postales de Barcelona está la foto de la Barceloneta que está haciéndose oscuro pero está iluminada la playa, yo creo que el hecho de que la playa esté iluminada le da esa calidad añadida, está iluminada desde la Villa Olímpica hasta el Hotel W, esto se hizo en 4fases diferentes, es decir, que el Port Vell está compuesto de proyectos muy diferentes, a partir de este primero y el segundo que es el Paseo Marítimo, pues seguimos haciendo el Muelle de Barcelona, donde está el Trade Center, el Muelle de Sant Bertran que es el que lleva desde el Muelle de Barcelona hacia el Sur, hacia el puerto, que luego continúa con el otro muelle que es el Muelle de Costa, que es yendo hacia la terminal de Italia, dentro de la Zona Portuaria.

Por otro lado hice la remodelación del Moll de la Fusta, que está en un lado, la parte superior, (la parte inferior lo remodeló otro arquitecto), dejando lo esencial evidentemente, la parte superior tenía muchos problemas, es un proyecto interesante del cual se puede hablar si hace falta, problemas que son importantes como la construcción del proyecto de espacio público y luego pues bueno las últimas fases, en zona ya portuaria, la parte del Paseo Marítimo que lleva al Hotel W, que es ámbito portuario, la Plaza del Mar que integra un aparcamiento subterráneo, el Paseo Marítimo que integra los clubs deportivos llega al Hotel W, la parte del Hotel W que la hizo todo un promotor privado pero son espacios públicos y la parte nueva de la Marina Vela la última, que también la hace un promotor privado, todo, pero está integrado con espacios públicos, con paseos, que se abrirá a final de mes, la parte del dique y todo eso se abrirá a fin demes, un sitio que no existía, lo que tiene el valor que tiene es un paisaje nuevo y ves Montjuic, ves el mar infinito, que es la parte de Ciutat Vella donde fuimos, la plaza aquella, por tanto, dos valores que hay aquí, uno es integrar infraestructuras como son puertos deportivos o marinas secas o lo que hay debajo de aquella plaza.

Ahora estamos desarrollando un proyecto en una ciudad pequeña comoes Mataró, que es integrar un depósito de aguas enorme;integrarlo con un parque, integrar infraestructura, integrar aparcamiento, todo esto con espacio público, es una oportunidad de poner en valor un lugar, pero también integrar elementos necesarios o imprescindibles que hace que funcione un espacio público, ¿también es necesario o imprescindible que haya una marina deportiva?, no lo sé, pero es lo que hay, lo digo porque esto hay gente que lo pone en cuestión, algún ecologista, no es que las 
marinas deportivas contaminan -ipero es que existen!- entonces si hay una marina deportiva es una oportunidad de crear un nuevo espacio urbano, por tanto no vamos a negar que los puertos tengan barcos, esto es como negar que tenemos que respirar, los puertos son para los barcos. Esto genera lugares de trabajo, genera nuevas zonas de ocio, si quieres, pero es una actividad urbana, como no sé, como los hoteles, o como el Liceu, o como los cines, o como lo que quieras, como los clubs deportivos, sean públicos o privados.

¿Cuáles la oportunidad? Crear nuevos espacios públicos, crear nuevos lugares, ¿que aquí pueda venir el Hermitage -que ojalá venga-?, pues imagínate la oportunidad de crear un nuevo centro urbano en un sitio que no existía, era el final del Puerto digamos, o de la playa, un rincón donde había gatos, había gatos y inada más!Es que hay gente que critica el Hotel W, y es que ihay hoteles en el mundo que le vamos a hacer! Lo que tiene este Plan es que se ha buscado una mezcla de usos, ojalá pueda ponerse el Hermitage, hay unos antiguos edificios que se van a restaurar, que puede haber co-workings, habrá algún equipamiento público, luego habrá un edificio mirador que será un restaurante, hay una mezcla de usos y un nuevo lugar.

Podría comentar sobre el tiempo de planificación y el tiempo de ejecución de los Proyectos de Espacio Público en Barcelona. Presupuesto inicial, costo final.

Bueno, es lo que te decía al principio, de la estrategia de Bohigas, de hacer proyectos realizables, en vez de un proyecto grande que tiene limitaciones económicas como es evidente, se hace por fases, a veces se hace por fases, cuando una cosa está en marcha facilita que la siguiente fase venga, en general esto es así, lo que te decía, el Paseo Marítimo solo lo que mira a la playa, se habrá hecho a lo mejor en 4 fases, pero al cabo de los años, los acaban haciendo.

Lo que tienes que hacer con el Proyecto es que tú cuando tienes un Proyecto, tienes que ver qué oportunidades hay aquí y aquí(señalando extremos contrarios de la mesa), y dejarlo abierto para que pueda continuar, tú no lo sabes, cuando estás haciendo el Proyecto, no tienes ni idea, como cuando hicimos la Ronda del Mig $^{14}$ en la primera fase, una cosa lineal que ya sabes que esto algún día puede continuar, pero cuando estás haciendo el primer proyecto no tienes ni idea. Tienes que dejarlo abierto, y evidentemente se acabó cubriendo con 4 fases más, pero no está dicho, pero sí quela experiencia enseña que, si una cosa no está mal, si funciona mínimamente bien, acaba continuando, pudiendo continuar.

Y esto es lo más importante, que los proyectos sean realizables, todo espacio público en general si son superficies grandes no es barato, lo hacemos de manera sobria, a veces se utiliza piedra natural, pero a veces no, otras veces utilizamos hormigón. En la plaza Berenguer o en la Calle Sant Pere Mès Baix, que también hice, es una calle así en curva medieval, es de granito porque se ha visto que es la piedra que funciona mejor en Ciutat Vella, donde se han utilizado materiales comola arenisca, las calles al principio eran de un prefabricado de hormigón, esto ya se ha visto

14.- Se refiere a la cobertura de la Ronda del Mig en la Rambla Brasil. Proyecto conjunto de Jordi Henrich y Olga Tarrasó de 1997. Posteriormente, este mismo equipo, prolongó el proyecto en la calle Badal (2001) y en la Avenida Carlos III (2002). Nota del Editor 


\section{on the w@terfront}

public art urban design civic participation urban regeneration

Moll d'Espanya, 1998

J. Henrich, Olga Tarrasó
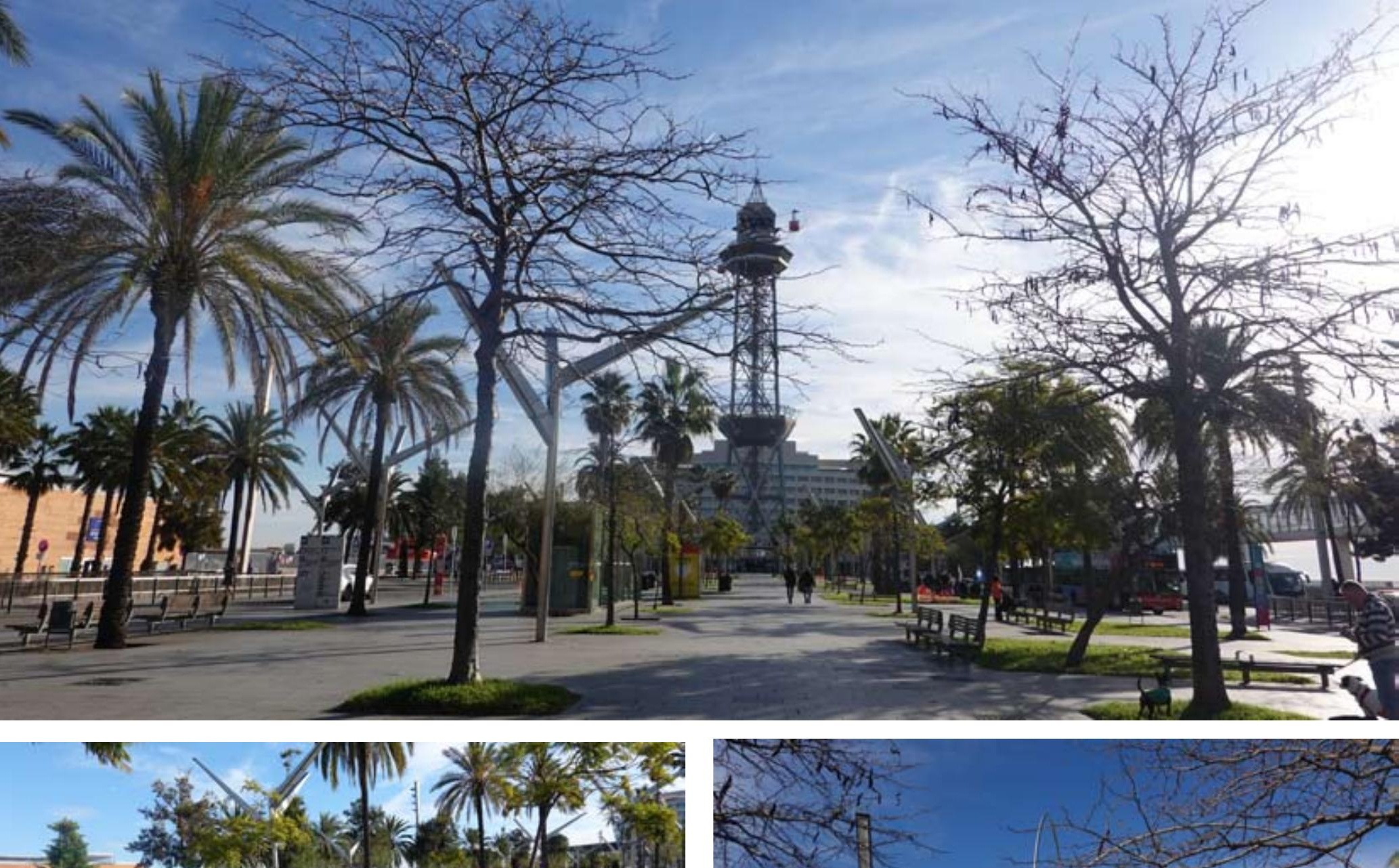

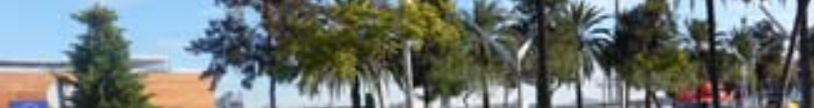

iI 3.
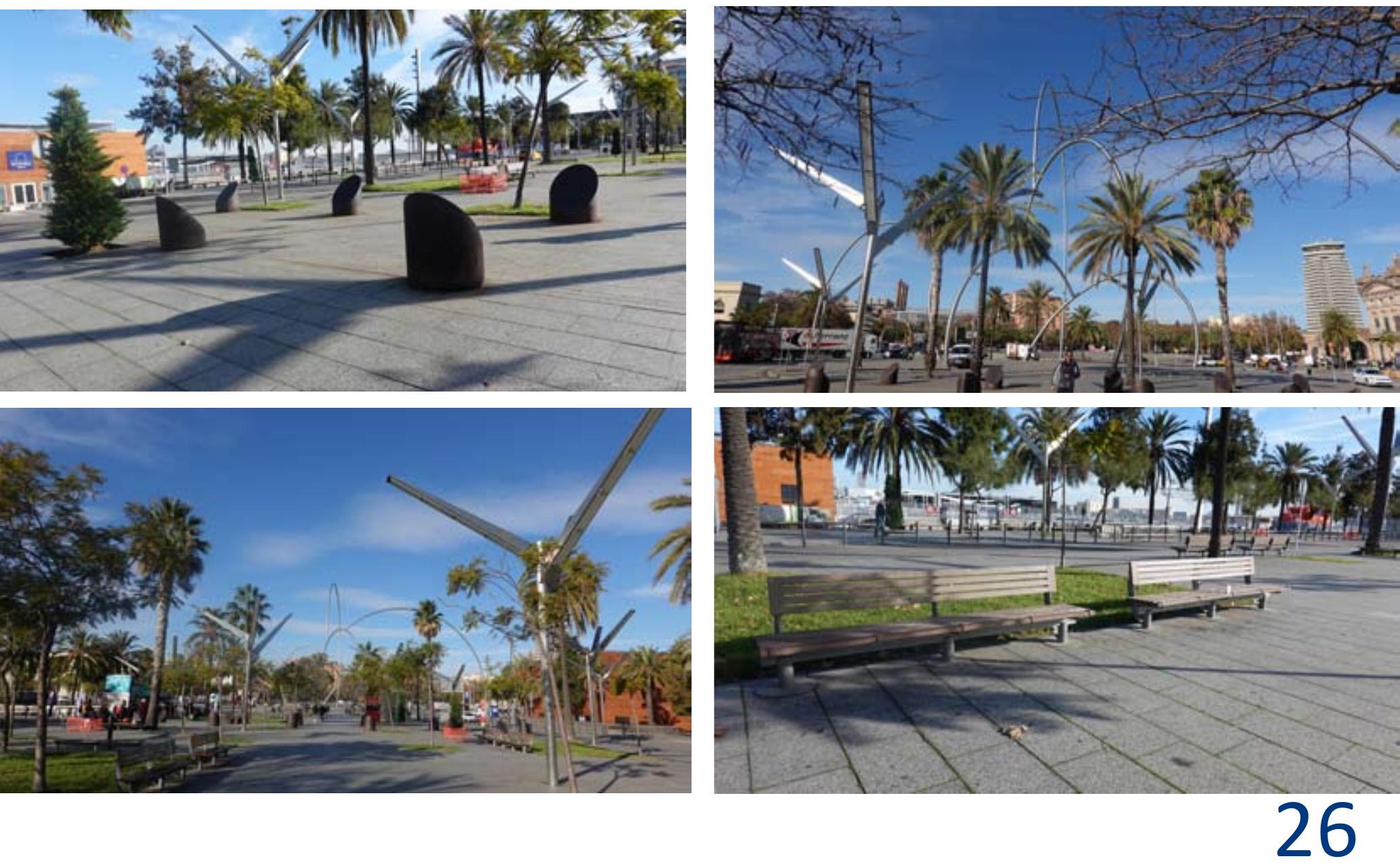

(ब) 9 
que no funciona bien en estas calles antiguas, en ninguna ciudad, en Francia se utilizó mucho y ahora se utiliza la piedra natural, es más caro, pero ya la calidad, la limpieza, la resistencia al uso, la baja porosidad, más vale invertir un poquito más, pero en estas calles medievales o peatonalizadas son de piedra natural, ahora en el resto de calles hay una casuística ya aceptada que es esta pieza de hormigón prefabricada de $20 \times 20$ que se va utilizando, por lo tanto ya es un pavimento normal-

Quiere decir que hay una calidad media, hay unas ratios, que más o menos están como ya en mente de todos, lo importante es esto que te decía, hay un tiempo corto para los proyectos y para las obras, y lo importante es planificarlo en este punto de vista.

\section{¿Participan las personas en sus Proyectos de creación de Espacio Público?}

$\mathrm{Si}$, y esto es esencial. Yo no he participado directamente en esos procesos, siempre ha habido gente a lo mejor que lo ha llevado a través del propio Municipio y por tanto los técnicos municipales o a veces los técnicos portuarios se han encargado de vehicularlo, lo que sí puedo decir es que,si el Proyecto está hecho con sentido común, con sobriedad, con lo que estamos diciendo, de poner al servicio de un barrio sea portuario o sea en el Distrito de Sant Martí, un espacio público de calidad que conecta, que crea espacios peatonales, que crea nuevos espacios donde no hay nada, donde hay espacios que no sirven para nada, esto funciona. No he tenido oportunidad de vivir temas conflictivos en ese sentido, y lo que se trata es de proyectar con esas premisas.

¿Cuál es el papel del arquitecto de espacio público, en el manejo de las obras de arte público que caracterizan Barcelona?

Bueno eso también, cada obra de arte tiene su historia. Una de las políticas de Barcelona, que ahora quizás se ha perdido un poco, es la creación del Arte Público de calidad, contemporáneo. Los socialistas a través de los Proyectos Urbanos ${ }^{15}$ se encargaron de ir implantando Obras de Arte Contemporáneo en el espacio público, y de ahí Remesar, hace muchos años empezó a trabajar con un arquitecto ${ }^{16}$ que estaba en el Ayuntamiento, en esta documentación y catalogación de la Web de Art Públic.

Esto ha habido historias muy diferentes desde la Cabeza de Liechtenstein, o El Gato de Botero que estaba dando vueltas por la ciudad, no sabían dónde ponerlo, había varias posibilidades donde ponerlo y al final la Cabeza de Liechtenstein pues acabó cuando se acabó la proyección de la ViaLaietana con el proyecto que hicimos y se puso ahí, porque quería ir a otro sitio. Hay otro ejemplo muy bonito como lo es la Plaza de Olga Tarrasó, la Plaza del General Moragues (1987), al lado del Puente de Calatravaen Sant Andreu, que tiene unas esculturas de Ellsworth Kelly, que es

15.- Se refiere a la unidad de gestión de proyectos que se creó poco después de la llegada de los socialistas al poder de la ciudad en 1979. Llegó a tener la consideración de Instituto de Proyectos Urbanos y fue dirigida por J.A. Acebillo(Bohigas, O- Puigdomenech,A-ACebillo, J-Galofré, J 1983; Subirós, Pep (Ed) 1993). Nota del Editor 16.- Se refiere a Ignasi de Lecea, fallecido en 2005, que siendo Director de Programas del área de Urbanismo del Ayuntamiento de Barcelona, impulsó el proyecto del Sistema de Información del Arte Público de Barcelona en colaboración con la Universitat de Barcelona.http://www.bcn.cat/artpublic . Nota del Editor 
un monolito y una $\mathrm{V}$, que está muy bien integradasen la plaza, que es una colaboración con Olga Tarrasó.

Y por ejemplo lo que hicieron en las Olimpiadas, de la Olimpiada Cultural, configuraciones urbanas que una Comisaria de Arte, que es Gloria Moure ${ }^{17}$, pues trajo a artistas de arte poveray minimalistas que actuaran en el lugar sin una escultura previa, evidentemente cada uno llevó no la escultura, pero su bagaje, cada uno actuó según su capacidad creativa.

Nuestro trabajo -que es lo que preguntas-fue el de un poco orientar a los artistas en aquel momento en la parte funcional, que la escultura en el espacio público no es un Jardín de un Museo, no es un Jardín de una Galería de Arte, no es un Jardín de Esculturas, no se cierra de noche, sino que está en un espacio público que tiene que funcionar 24 horas al día, y por tanto le decíamos muy educadamente los límites del espacio público, es decir que no fueran agujeros en el suelo o que no fueran barricadas, o que no fueran laberintos en medio de una plaza, que serían lugares que se degradarían, evitar la degradación.

¿Cuál es su opinión sobre los Concursos de Diseño de Espacio Público? ¿Internacionales? ¿Restringido? ¿̇ crear un buen equipo técnico municipal? ¿O con colaboraciones?

Yo creo que es un poco cruel, porque me esfuerzo mucho y no obtengo los resultados que quisiera.

\section{¿Muchas veces están arreglados?}

Pues sí. Lo que yo digo, desde el punto de vista del arquitecto, creo que el arquitecto -además si quiere apuntar a Proyectos Públicos- tiene que hacer un Concurso, que muchas veces está arreglado, pero es un ejercicio que hay que hacer, tenemos que acostumbrarnos, es muy duro, seguramente muchos profesionales deben quedar alucinados de que mucha veces trabajemos gratis y esto es parte de nuestro trabajo, yo creo que es la oportunidad de reflexión, de ejercicio, de fuerza moral, de crear equipos, de crear una experiencia que se va sumando, creo que lo más importante es hacer algo que te cree un bagaje, tanto si es de edificios como si es de espacios públicos o de paisaje, de crear un bagaje, que sea algo que enriquezca tu experiencia, y que te vaya enriqueciendo y lo puedas luego desarrollar o aplicar en otro proyecto, que sume también a tu currículum, yo he hecho todo tipo de Concursos Internacionales, Moscú, Copenhague, París, no he dicho que los he ganado, pero he estadoa punto, creo que tenía que haber ganado, entre paréntesis, no todos, pero sí algunos, pero quizás no tengo el porcentaje de ganadores que merezco, pero hay que hacerlo, y además es muy enriquecedor.

Luego ya te digo hay concurso de todo tipo, hay concursos que te pagan. Los franceses en general, escogen a 3 o 4 equipos y te pagan, en general, antes tienes que presentar una propuesta, una memoria, etc. En Italia, es más desordenado y no te pagan. En Dinamarca nos escogieron en uno muy importante y también nos pagaron bastante bien. En Suiza, hicimos abiertos y también ganamos 
y allí pagan muy bien, era abierto, es decir que era arriesgado, ahí arriesgamos mucho trabajo puesto que quizás no ganábamos nada. Hicimos un Concurso en Ecuador, el Parque Samanes, muy grande, un parque tan grande como el Central Park de Nueva York, luego nos marchamos porque nos echaron, hicimos un buen proyecto incluso lo han construido sin nosotros, esto es frustrante, sí, pero ahí está, y es un Gran Proyecto de Parque y lo han construido con una parte según nuestros diseños. Resumiendo, todos los desengaños que puedas tener, que no te ponen en valor tu trabajo, que al final lo ponen en valor porque construyen lo que has proyectado, esto suma, y como arquitectos debemos ser conscientes que no podemos hacer todos los concursos, porque si no sería una ruina, pero si mezclamos un poco del trabajo que te pagan con este que abre nuevas puertas, es lo que hay que ir haciendo y no perder la ilusión nunca aunque sea difícil.

En mi país, Paraguay, por ejemplo, como los concursos los ganan equipos distintos queda una ciudad con espacios públicos muy distintos entre sí. Entonces la ciudad no queda homogénea.

Pero eso está bien, otra cosa es que los proyectos sean correctos, apropiados, que transformen positivamente y no sea un ejercicio al propio ego, un ejercicio inútil. No sé si preguntas algo de las Supermanzanas, pero que evidentemente los espacios públicos pueden ser diversos.

¿Qué es un ejemplo de espacio público en Barcelona? Yo pondría como siempre la Plaza de la Catedral ${ }^{18}$, ¿ por qué? porque es sobria, es abierta, en esa plaza pasa de todo, hay arquitectura, hay permeabilidad del barrio y al mismo tiempo integra una infraestructura importante de aparcamientos, sin que prácticamente se note que está allí, que esto no es muy habitual en muchas ciudades. ¿Que esto es diferente que otra plaza que hay aparcamientos? Claro, la Plaza Joanic tiene un jardín con una plaza de barrio de Gracia, y el jardín debajo tiene aparcamientos. Las dos son ejemplos como puede haber 30 más.

Pero esas dos plazas son representantes de espacios públicos de Barcelona, la Plaza de la Catedral tiene 27-28 años y parece que se terminó ayer, ¿’por qué? porque es sobria, la permanencia de los diseños, tiene que ser sobria, porque lo que es sobrio no pasa, se mantiene en el tiempo, es atemporal.

Volviendo al tema del Port Vell, ¿Cree que los topmanta degradan el espacio urbano o le dan una dinámica distinta? ¿Y los skaters?

Pero si el carril top manta se ha puesto muy ordenadamente (entre risas). A ver, los skaters vienen, no sé por qué vienen aquí, luego en la plaza del MACBA resulta que no es una plaza para skaters, pero acaban viniendo. Luego los skateparks que tienen mucho éxito.

En la Plaza de Berenguer también vienen los skaters que al final van dando saltitos en los escalones. A mí mientras no estropeen las cosas, a veces es un poco que, si no molestan a los demás, no me molestan. Pero, si se empiezan a romper cosas, si voy a un banco con una sierra, y hago así, es 


\section{on the w@terfront}

public art urban design civic participation urban regeneration

Plaza Ramón Berenguer, 2017

J. Henrich
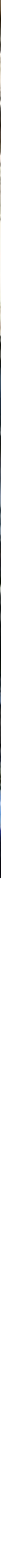

1)

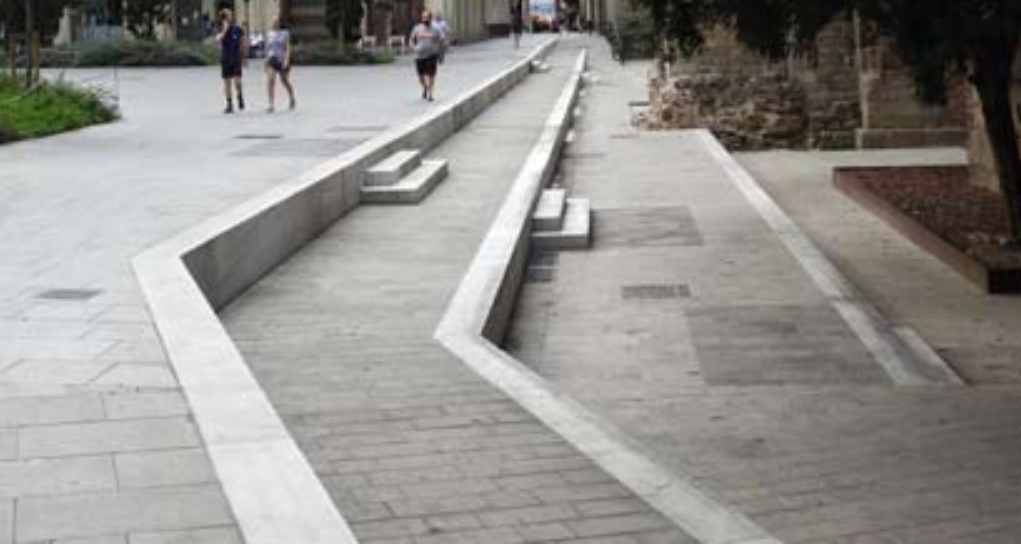


lo mismo que un skater que le va dando a un banco de madera, ahítiene que haber un poco de disciplina, un poco de control.

Es un problema como de los que decíamos, social, como el tema de la vivienda. ¿Cuál es la solución al top manta? Pues no lo sé, no sé si hay otra ciudad que tenga la solución, pero no sé cuál es. El top manta lo que vemos es la fachada, luego depende de unas mafias que fabrican los productos y que los venden y todo eso, no sé si en otra ciudad de Europa también existe. Aquí se intenta controlar, pero no se controla nada. Han fichado unos cuantos que les pusieron un uniforme a arreglar fachadas, que me parece muy bien. Otra cosa sería intentar regularizar esto y dignificar su trabajo, y no sé cómo se tiene que hacer, pero también son fraudulentos, por tanto, me decían los del Puerto es un problema. Es un problema porque hay mucha suciedad y eso sí es un problema. La otra vez me preguntaban desde el Puerto ¿Qué solución le pondrías? Algunos me decían que sean parte del mantenimiento de la Barceloneta. No lo sé, no sé cuál es la solución. Es parte del uso abierto de espacios públicos.

Hay países como Dinamarca, que en Copenhague ponen pistas de básket en las plazas, y las cierran de manera artística porque a lo mejor hace mal tiempo, o porque a lo mejor ya no utilizan tanto las plazas, no lo sé, pero a ellos les gusta que las plazas tengan equipamiento deportivo. Para mí digamos, particularizar un espacio y de un espacio público que lo puede utilizar el $100 \%$ de la población, esto pasa a utilizarlo el $0,01 \%$, que son los que juegan básket, que me parece bien, pero es que eso está puesto en Copenhague en la plaza central en medio. Poner el básket en un rinconcito para que puedan jugar tranquilamente ahí entre los árboles, el espacio público tiene que poner en valor el lugar, es un Ágora, no podemos llenarlo de trastos.

¿En el espacio público, es más importante el valor de uso o el valor de cambio (búsqueda de obtener un beneficio como si el espacio público fuera una mera mercadería)?

El espacio público es como un contenedor de lo público y desde lo público hay una cosa que es el comercio, que son las fachadas, luego hay lo que pasa en el Paseo Marítimo, o en estos sitios abiertos a paisaje o en los parques hay unas necesidades que se pueden complementar, como es la presencia de pequeños quioscos donde hay bares, o restaurantes como los de la playa, que en invierno se quitan, ese es uno de los diseños de Barcelona, quiosco tipo Habana ${ }^{19}$, que está muy bien diseñado, que son muy funcionales, mínimos, con sus pérgolas para proteger y crear el ámbito de terraza, otro de los temas es ordenar las terrazas de manera que los espacios públicos puedan disfrutar de este uso complementario de estar sentado al sol o al aire o a la sombra y disfrutar de la terraza como todos los espacios cívicos.

Esos son los usos que hay que ordenar, es decir, y ordenar quiere decir buscar un equilibrio entre todo, es decir no puedes llenar el espacio público de quioscos, es evidente porque lo destrozas, pero tampoco puedes hacer espacio público y no hacer terrazas, debe haber un equilibrio, igual que el mismo equilibrio de la movilidad. $Y$ en el equilibrio de movilidad ahí entraremos en el

19.- Habana es un quiosco, con o sin pérgola, concebido como punto de servicio en playas, parques o amplios espacios urbanos desarrollado por Microarquitectura. Nota del Editor 


\section{on the w@terfront}

public art

Carrer Sant Pere més Baix, 2015

J. Henrich y equipo
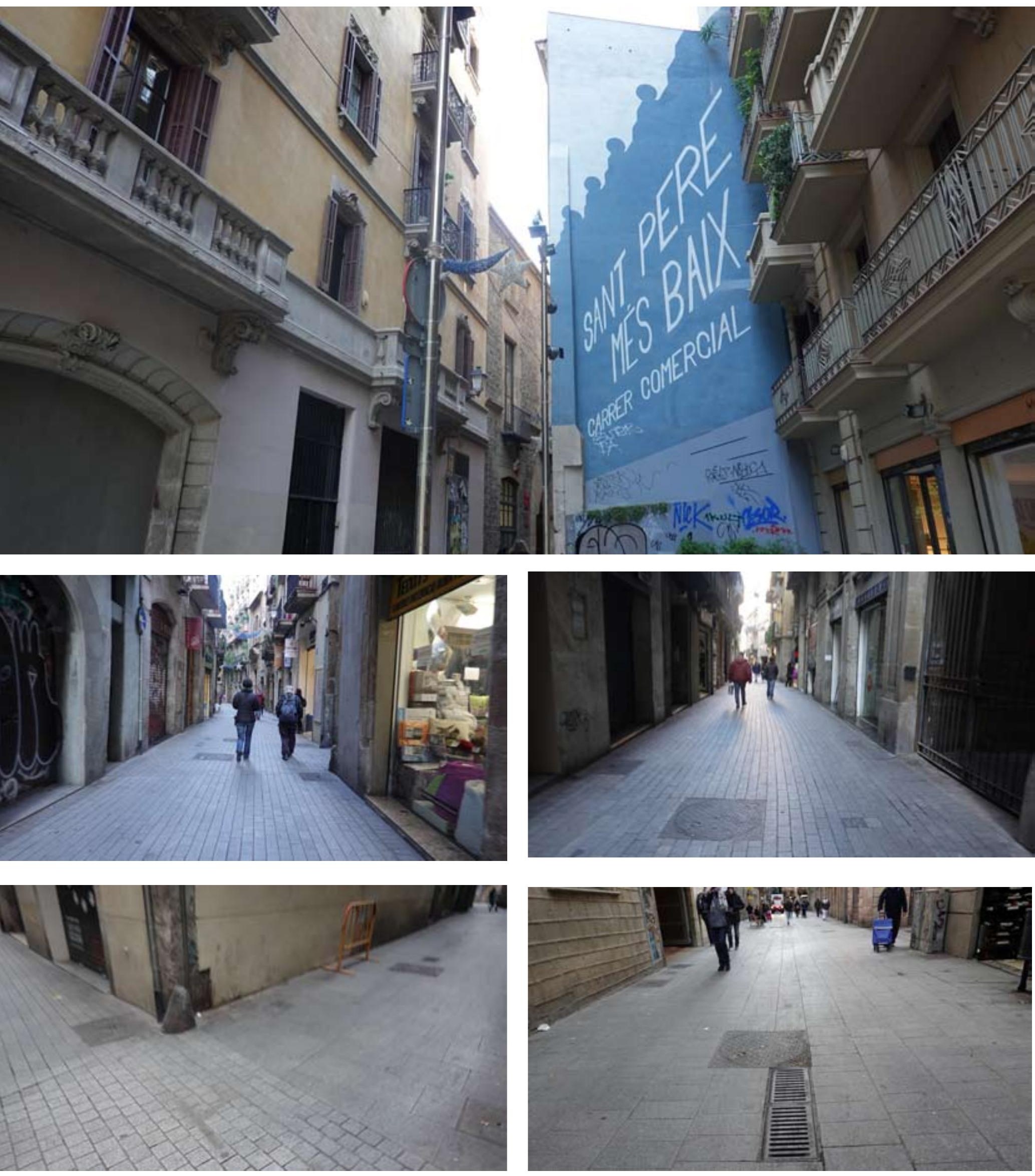
tema del tranvía, el tema del tranvía que se cree que sea la solución de no se sabe qué, pero el tranvía digamos destruye la movilidad vehicular, privada o pública, transporte público y transporte privado que es imprescindible en la ciudad y para solo implantar el modelo de transporte público, eliminando el transporte privado y ahí yo no estoy de acuerdo, porque si esto fuera un elemento transparente que flota en el espacio, te diría vale, pero si esto implica poner vías, implica poner unos trenes en medio de la ciudad, yo te digo no, no vayamos a poner trenes en el siglo XXI, en medio de la Diagonal, en una ciudad densa, muy densa, hay una cosa que se llama autobús eléctrico, así que no nos vengan a vender ahora un transporte público que además tiene intereses privados. Que ahí entraremos en otro tema, que me gustaría saber por qué hay tanto interés en el tranvía, porque yo he preguntado en el Ayuntamiento que me expliquen por qué es mejor el tranvía que el autobús eléctrico y sin respuesta. Despachan el autobús eléctrico diciendo que tiene poca capacidad, y eso es mentira, porque falta ver si realmente si se necesita tanta capacidad, cosa que dudo, porque no sé si hay tanta gente interesada en atravesar Barcelona, no lo sé, pones más autobuses eléctricos y ya está, una flota de 8 y si tiene mucha demanda poner más, es así de sencillo.

Esto del modelo del tranvía yo lo veo como el Metrobús de Curitiba o de Porto Alegre, que como yo lo he visto, el de Porto Alegre, en que mediante e un modelo de transporte público se puede destrozar una Avenida. ¿Por qué? Sí, se necesita transporte público, si yo sé, pero no hagamos demagogia, porque lo que no podemos hacer es destrozar una Avenida porque por ejemplo ponen las paradas en medio de las calles, ¿Porqué es el transporte público? No, pero la calzada tiene que funcionar, entonces hay que buscar un equilibrio entre las funciones, que evidentemente queremos que haya la mitad de coches, iyo firmo ahora lo que haga falta!, a mí me encanta el mes de Agosto, cuando hay la mitad de coches en Barcelona, hace unos años no había nadie en Barcelona en Agosto, tú venías y quedabas alucinado, porque como no había turistas y los de Barcelona se iban todos, era alucinante. Paseaba por la Diagonal a los 19 años y no había nadie, muy bonito, se te queda grabado, ahora no pasa así, pero que hay que buscar un equilibrio entre todas las funciones, sean quioscos o sean tranvías.

\section{¿Cómo se mueve Ud. en Barcelona?}

En metro. Pero si necesito ir fuera, pues tampoco me flagelo, cojo el coche, pero lo mínimo, porque además como tengo que aparcar, el parking de la Plaza de la Catedral es caro (se ríe), y esto ayuda a no cogerlo. Yo soy militante del transporte público evidentemente, precisamente porque soy militante del transporte público el tranvía es un modelo acabado, yo no lo utilizo porque no está en mi recorrido, yo lo he visto y sé que es lento, y he subido alguna vez, pero el autobús es mucho más funcional, y es flexible, y va y sale, y si hay un coche aparcado se mueve, en fin, funciona bien, y cada vez son más híbridos, a gas, eléctricos, etc.

Es muy importante que esto pase en ciudades latinoamericanas, como por ejemplo San José de Costa Rica, que es que el transporte público sea ordenado y que sea público, lo que no puede 
ser es que el sistema de transporte público sea privado y cada uno monte su historia, y sea un caos alrededor del centro de la ciudad, y esto no puede ser. Entonces si alguien reflexiona sobre esto, evidente hay compañías de transporte privado en todas partes, sobre todo de autocares interurbanos, pero esto hay que ordenarlo, no puede ser un caos. Pero sobre todo el transporte urbano tiene que ser público. Entonces yo creo que el de Barcelona está bastante bien. Hay autobuses nuevos con aire acondicionado, el metro va bien. Ahora los autobuses funcionan mejor, sabes cuánto tardan, bueno esto es parte también de la política de espacios públicos, de pensar la ciudad en función de lo público. Igual que por ejemplo los taxis, hace años había unos taxis viejos, con un conductor que fumaba un puro y el taxi era un pestazo de puro y te empezaba a hablar de fútbol, era un taxi donde decías: -No sé si voy a subir. Ahora están bastante bien, son caros, no son baratos, pero no están mal, a lo mejor el conductor es un pakistaní que no sabe dónde está la calle (se ríe), pero están bastante cuidados. También es una cuestión que está bastante cuidada desde el Ayuntamiento.

Ud. es una persona que está bien informada y que ha viajado mucho. ¿Qué ciudad le ha sorprendido en materia de mejora de espacio público?

Mucho no, ino tanto como tú! Tampoco he viajado tanto. Creo que las ciudades de Latinoamérica, bueno lo poco que sé, el tema de recuperar espacios que estaban cerrados a la ciudad, es una algo que con más acierto, o menos, se intenta; intenta; la ciudad de Río de Janeiro ha recuperado el muelle, que antes era portuario, como espacio abierto.

Todas las ciudades de una manera u otra van interviniendo, creo en el espacio colectivo, no sé si público o privado. Hicimos un concurso que no ganamos tampoco, en Grenoble, en Francia, donde hay un problema urbano de un gran hipermercado con un entorno muy degradado, donde estaba la Villa Olímpica de Grenoble, entonces ahí se está haciendo un Concurso para crear una Nueva Centralidad. Es que, en Francia, es evidente que hace años que están haciendo intervenciones en el espacio público, en Lyon, que creo que sícopió el Modelo Barcelona, se han puesto en valor las márgenes del río, con las gradas, los paseos, que han abierto todavía más, se han hecho nuevas calles peatonales, ejes peatonales, es decir que poco a poco ves que en diferentes grados muchas ciudades están haciendo cosas.

Esto es positivo, ahora, ¿cuál es la que hace más? No lo sé, pero sí que podemos pensar que Copenhague es ejemplar, en el sentido que mucha gente va en bicicleta y esto está extendido y que hay una conciencia muy grande en no coger un coche, cosa que en Barcelona no pasa, hay mucha gente que sigue cogiendo el coche, aunque yo pienso que la mitad podrían ir perfectamente en transporte público, pero tenemos este ego mediterráneo que obliga a ir paseando el coche y contaminando, es que si fuera eléctrico todavía, pero vamos contaminando. A mí me alucina, que alguien tenga una máquina para contaminar y que la utilice cada día, hay gente que no coge un transporte público, esto seguramente si vamos a Dinamarca, que es probablemente el país más socialmente equilibrado, este ego de yo soy más rico porque voy en coche, no existe, y esto si vamos al otro límite que es, algunas ciudades en que si vas a pie eres un desgraciado. 
¡En un país como el mío! En muchos países en vías de desarrollo como el mío, el coche es visto como un símbolo de estatus social, como se podría prevenir a tiempo en estos países de cometer los mismos errores que se cometieron aquí en Europa.

Bueno, creo que el tema por un lado es social, no tienes que estar paseando con tu coche para mostrar tu status, pero por otro lado tiene que haber un espacio público de calidad que acompañe, porque a ver, ir a pasear según a qué sitios no voy, o porque tiene la acera de 1 metro y 8 carriles que te pasan al lado, tiene que haber unas condiciones de calidad de espacio público que hace que la mayoría de gente pueda pasear por ese sitio.

El paradigma son las Ramblas donde hay demasiada gente, pero quiero decir que el Paseo de Gracia es agradable porque puedes pasear, en la calle Aragó antes tenía veredas muy estrechas, una de las cosas que se va haciendo en Barcelona, que te decía que se siguen haciendo cosas, es ensanchar las aceras, la calle Balmes tenía aceras de $2 \mathrm{~m}$, y se fue ensanchando eliminando un carril de coches, que son $3 \mathrm{~m}, 1,5 \mathrm{~m}$ por aquí y $1,5 \mathrm{~m}$ por aquí, pues plantas árboles y cambia radicalmente. Entonces puedes ver la diferencia de Gran Vía para abajo hasta Pelai, que todavía tiene aceras estrechas, no es que sea una calle horrible, pero es una calle que pobrecita y ahora lo que es de Gran Vía para arriba que tiene las aceras normales, que me digas que esto tiene un valor, tiene el valor de haberlo hecho. ¿Se hace esto en todas las ciudades? No lo sé, pero es que es una algo que pueden hacer todas las ciudades, cualquier ciudad puede hacer eso, creo que cualquier ciudad que diseñe una estrategia con unos calendarios y una planificación de empezar a establecer ejes, un sistema de renovación de ejes, poniendo en valor los espacios peatonales, es esto, eliminar un carril, eliminar dos carriles, es lo que está haciendo la Meridiana también, para poner el carril bici en medio, la Meridiana ya se remodeló. La Meridiana ${ }^{20}$ era horrorosa, era una carretera en medio de la ciudad, unas aceras estrechas, se hizo la remodelación en forma de bulevar hará unos 15-20 años, apareció que no es suficiente, sobre todo creo yo porque el carril bici al principio no se puso bien, tenía demasiados intríngulis, demasiados cambios, supongo que porque apareció a último momento.

El carril bici hace unos años no se pensaba, luego empezamos a poner en el Paseo Marítimo frente al Hospital de Mar, ahí lo integramos quitando un aparcamiento, estas cosas hay que aprovecharlas. Los espacios públicos hay que empezarlos por la sección, se coge la sección y se mira cómo se puede eliminar un carril y cómo se pueden ensanchar espacios para cederlo o al ciclista o al peatón_. Y esta es una estrategia que en muchas ciudades se podría empezar haciendo, gente documentada y con visión como tú.

Podría hacer un comentario sobre justamente la estrategia de Barcelona de realizar los parkings subterráneos y aprovechar la superficie para la creación de espacio público.

Hay una cosa que es muy importante de la política de Barcelona de espacio público, y es que

20 Proyecto de remodelación en dos fases (fases (1995 y 1999) realizado por A. Montes, M.Periel, C. Fuente; D.Domènech. 


\section{on the w@terfront}

public art urban design civic participation urban regeneration

Parque de la Barceloenta, 1994

J. Henrich y equipo
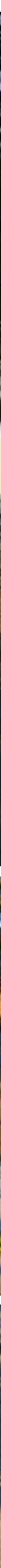

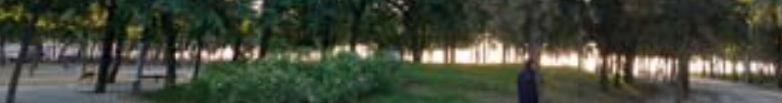

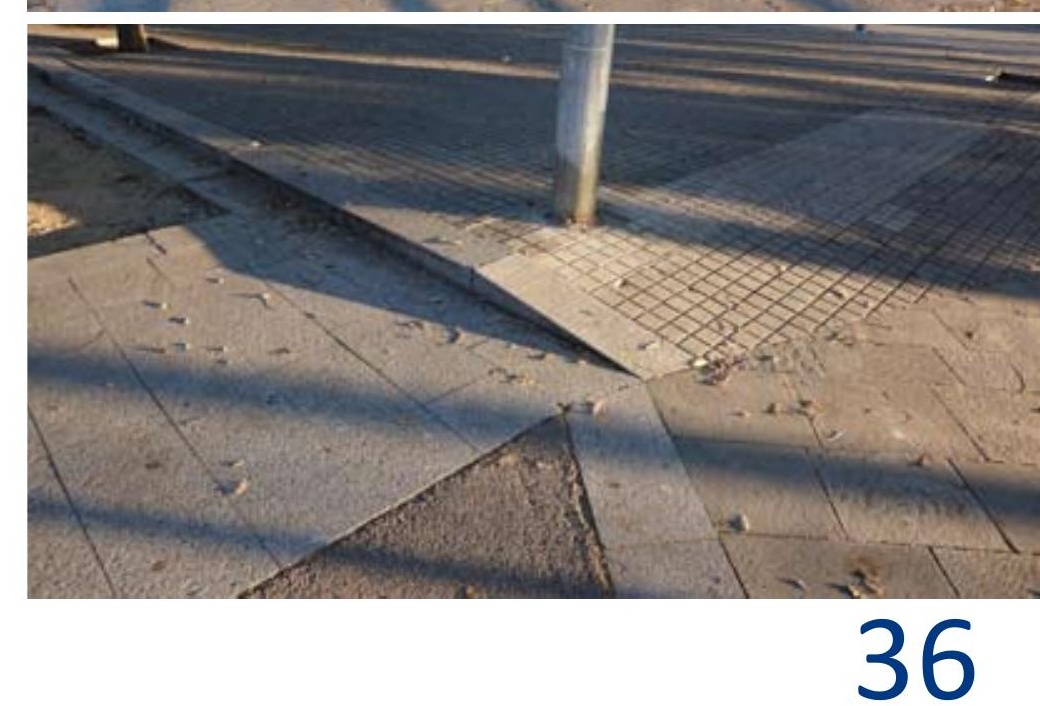

(c) (i) Publicado por el POLIS RESEARCH CENTRE. Universitat de Barcelona 
esto genera, como te decía, un sentimiento de pertenencia de los ciudadanos, pero también genera una capacidad de hacer cosas; es decir, si se plantea la biblioteca cercana al mercado de Sant Antoni, tan bonita, se plantea que la Biblioteca ${ }^{21}$ resuelva una entrada, al mismo tiempo, a otra tipología de espacios públicos que son los jardines de interiores de manzana del Eixample, que antes no existían. Se empezó uno que está en la calle Llúria y Diputación, que tiene la torre de agua ${ }^{22}$, con aquel se empezó, y ahora hay un muchos, es decir, que ahí se generó una idea de espacio público y de interiores de manzana, y en algunos que se ha puesto una guardería, un kindergarten, en la Biblioteca de Sant Antoni, hay un local para la gente mayor, hay un jardín muy bonito, pequeñito, esto es una tipología interesante.

Tu preguntas la tipología de los parkings, lo que te decía antes, la Catedral, la Plaza Joanic, el Jardín que hay en Mitre con Numancia ${ }^{23}$, más arriba de la L'Illa Diagonal24, que es un jardín ondulado donde están las cocheras de Coderch, ahí debajo hay un parking, o los parkings que hay en Zona Portuaria, en el Moll de la Barceloneta hay un parking que lo integramos con el paseo, hicimos la piscina de tierra y ahí se plantaron los árboles, entonces el trabajo de parking es muy importante porque permite cubrir o generar usos. ¿Que tenemos que tener parking? Sí, hay gente que estaba en contra del parking de la Catedral y dice "no tenemos que venir en coche al centro", pero hay gente que viene en coche y está siempre lleno, hay gente que dice "no hagamos el parking”, pero es que si hay que hacer un parking lo hacemos, igual que la Marina, "es que no debe haber una Marina" ipero es que si hay barcos! Entonces hagamos una cosa, hagamos que esto sea una oportunidad para la ciudad.

Y los parkings son una necesidad, entonces se han hecho muchos parkings que son de concesión a 50 años, para los barrios, yo he participado en la zona de Nou Barris, (hace años), de Sant Martí, de la Plaza de la Verneda, se hicieron muchos, y sobre ellos la plaza. Los parkings son de empresas privadas, pero con un control digamos, que es que el proyecto de parking tiene que estar de acuerdo con el espacio público, es decir las entradas de vehículos, los accesos de peatones y el proyecto de espacio público tiene que estar todo integrado, o sea no se improvisa, porque sería un desastre, y por lo tanto la rampa está bien puesta, los accesos también, y luego se deja 1,5m de tierra para plantar árboles, porque esto hay que asumirlo desde el punto de vista de la estructura, la Plaza de Mar es así, hay $1 \mathrm{~m} . .1,5 \mathrm{~m}$ de tierra que luego va bajando, allí hay una limitación con el mar, hasta la cota 0 porque si bajas es muy caro, y por eso la plaza sube suavemente, está más alta de lo que estaba antes, hay condicionantes como te decía, en el Trade Center, pues también hubo el parking, colaboramos con los ingenieros, el parking está en pendiente y sube hasta el Trade Center, porque el Trade Center está a una altura de 1,5m respecto al muelle, entonces todo el paseo sube imperceptiblemente hacia la cota 0 de la planta baja y todo el parking lo acompaña.

Es decir que el proyecto de espacio público tiene que guiar el proyecto del parking.

21.- Biblioteca Sant Antoni- Joan Oliver de 4171.0 m2. Proyecto de RCR Arquitectes, 2007. Nota del Editor

22.- Hace referencia al Jardí de la Torre de les Aigues, proyecto de C.Ribas y A. Arriola, 1987. Nota del Editor

23.- Se refiere a los Jardines Joan Vinyolí, proyecto de C. Casamor y M. Gabas, 1998. Nota del Editor

24.- Proyecto de Rafael Moneo y Manuel de Solà-Morales, 1993 
El de la Plaza del Mar igual, los accesos, se salvaron los árboles. Igual en otros sitios hubieran cortado los árboles, en el Moll de la Fusta ${ }^{25}$ hay otro parking, y en la Ronda del Mig, primer tramo que se construyó, antes era un paseo normal, en los años 70 que decíamos que mandó el vehículo, se hizo la Ronda del Mig como una gran zanja, como una autovía, en ese momento seguramente en la ciudad había muy pocos coches, pero era un desastre porque una gran herida en la trama urbana, entonces los vecinos,-fueron al Ayuntamiento y dijeron:- Queremos que se cubra la Ronda del Mig. Claro que sí porque había espacio, que si se podía cubrir, esto fue después de las Olimpiadas, entonces había un político muy bueno del Distrito, yo no sé muy bien cómo fue, pero salió la posibilidad de que se cubriera con un parking, o sea, debajo de la primera fase que está más levantada, hay una sobre altura, que permitió meter el parking, los parkings son bajos, son de una sola planta, son de $2,3 \mathrm{~m}$ o 2,4m y entonces se metió un parking que solo sale alrededor de 1 metro de la rasante de la calle y el proyecto se hizo gracias a que se hizo un parking, y entonces como fue, organizaron unas sesiones de ciudadanos, donde se explicó el parking, se explicó el proyecto de paseo, esta primera fase que te decía que no sabíamos si iba a continuar y todo coordinado con el arquitecto que hacía el parking, que era de una empresa privada de parkings, como el de la Catedral, que se llama SABA, luego hay otra que se llama BSM que es municipal, y otras.

Entonces el compromiso que estableció el ayuntamiento fue que si se vendían a los vecinos la mitad de las plazas de aquel parking, que no sé cuántos eran, se empezaba la obra, la empresa SABA se comprometía a empezar la obra, entonces ya en 15 días los vecinos compraron esto y se empezó la obra y se pudo cubrir la primera fase, la segunda fase se hizo también con el que ya era hacia arriba, el barrio que es Les Corts, más nuevo, quizás más rico, con edificios más nuevos, siendo también el anteproyecto con un parking, pero no salió, la gente no compró, entonces ahí se pidió dinero a la Unión Europea para eliminar la contaminación acústica, en lugar de pantallas poner una losa y la Unión Europea pagó el $80 \%$ de la losa que cubre el tramo superior a Brasil, que es Carles III, hasta Travessera de Les Corts, y el tramo inferior cerca del tren, ahí se cubrió con la Unión Europea.

Y luego una última fase, que el Ayuntamiento dijo ya basta, no cubriremos más, pero los vecinos pidieron que continúe, que tenía que haber llegado hasta la Diagonal, y esto ya lo pagó el Ayuntamiento, la losa y todo, porque Europa ya no pagó más, pero el parking en ese caso sirvió para cubrir la Ronda, es importante eso. Pero fijate ahí en la Ronda, incluso había un proyecto de poner una piscina, es que pasa el tren, bueno ahora está integrado con aquel cajón, que bueno está mal, el tren debería haber ido subterráneo, por mucho que pongas un cajón, ese es uno de los límites yo creo que Barcelona, que puedes ver, que cualquiera puede entender, lo que está bien y lo que no está bien. la Ronda del Mig se hizo en zanja, se creó un paseo que está a nivel de lo que es una rambla, encima cubriendo los coches y no es que no tenga árboles, tiene árboles y buscamos la manera de poder plantar árboles encima de una losa, de $1 \mathrm{~m}$ de tierra, no más, con unos parterres y tal, que son grandes macetas, grandes maceteros, y crear un eje central que es 
un paseo que se va abriendo y tal, tiene un poco de topografía y tal, a veces tiene escaleritas, integrando todo y las ventilaciones, el parking, aquello de la fase primera que da a Brasil que está más elevada, me acuerdo que cuando hicimos el primer muro, vino el del barrio de adelante, y este muro es para plantar árboles, hicimos un buen render especial, un muro de 1,5m, desde el lateral ves la gente que pasea en el centro y viceversa, entonces si tú este paseo en lugar de verlo a $1 \mathrm{~m}, 1,5 \mathrm{~m}$ de la calle lo tienes a $3 \mathrm{~m}$, cambia radicalmente, ya es un sitio donde a lo mejor te piensas si vas, por qué, porque no ves de una manera inconsciente, no tienes que analizar, ni llegar a conclusiones, tienes que darte cuenta que hay una relación, por tanto si hay desniveles tienen que ser siempre los más bajos posibles, buscar una conexión.

Cuando dices que el tren entra en Barcelona, el tren no es un elemento urbano, en el siglo XXI, a lo mejor si en el siglo XIX sí, pero aquí alguien se equivocó, alguien importante del Ayuntamiento, dejó que el tren, se trae el AVE, y toda esta historia que estuvimos no sé cuántos años hablando del AVE, entrara a Barcelona en un cajón elevado, no sé si dejar el AVE, o dejar los otros, tú no puedes cubrir un tren con un cajón, esto es una muralla, que arriba haces un paseo, bueno si, maravilloso, pero estás haciendo una muralla, es decir que podemos tener buenas palabras y si escuchamos a los que diseñaron el cajón, o los que lo originaron te dirán magnificas palabras, pero el proyecto es como decíamos de los buenos arquitectos o la buena arquitectura o los buenos espacios públicos, no me expliques cosas, solo dime a ver qué cosas vas a hacer, a esto le ponemos una fachada de vidrio, esto es una muralla, el tren tiene que venir enterrado, como es el tren en la calle Aragón, está enterrado, el tren en Barcelona, imagínate que el tren estuviera en la calle Aragón.

Esto puede pasar en muchas ciudades, en muchas ciudades que para hacer un cruce viario hacen un puente, esto lo vi en Guayaquil o en Quito, eso se soluciona con un semáforo, en Moscú, los peatones tienen que ir por debajo, porque las calles son como avenidas que no paran, son autopistas incluso, tienen la mentalidad de que una calle es una avenida, una autopista, si no hay un cruce de coches, los peatones cruzan por debajo. Pero los pasos tampoco es que estén muy mal, porque como lo utiliza todo el mundo, a veces hay comercios, así como los metros, algunos tienen escaleras mecánicas, los minusválidos no acceden aquí. Lo que quiere decir es que eso es muy fácil de arreglar, pones semáforos.

Una vez fuimos al campus de la Universidad en San José de Costa Rica y había unos arquitectos jóvenes que hacían una maqueta de una plaza muy bonita, llena de árboles, como si fuera una Supermanzana, tenía una pequeña avenida y ponían un puente peatonal, y digo este puente peatonal para qué sirve, existe algo que se llamaba semáforos. Pero incluso aquí, hay grandes arquitectos y paisajistas que a veces hacen un puente que no está justificado. El espacio público tiene que ser sobrio. No hagas un puente sino toca, no está justificado, una cosa es que digas, es que tenga una cosa aquí, y otra aquí y aquí pasas una autopista o pasa un tren, vale, no lo puedo cambiar, entonces construye un puente. O hay, un rio, o hay un canal, pero si es una calle normal hay una cosa que se llama semáforos, no gastes esfuerzos en poner cosas inútiles, haz unas 
Rambla del Poblenou, 1991-2001

J. Henrich, Olga Tarrasó, Marta Gabàs
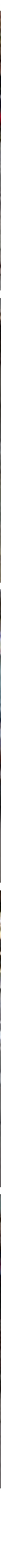

(c) 
buenas aceras, haz un jardín, haz lo que quieras, pero para cruzar la calle se usan semáforos. Lo que estoy diciendo son cosas obvias, pero lo digo porque hay gente que se olvida de esto.

Podría dar su opinión respecto al modelo de ciudad de las Supermanzanas ${ }^{26}$.

Resumo todo lo que decimos, a ver como lo has visto, yo fui a ver la Supermanzana esta del Poble Nou cuando se acabó, que fue en setiembre del año pasado (2016), es que hicieron varias correcciones-ahora no recuerdo los detalles de cómo es, no sé si son, cuántas manzanas son, pero no funcionaba, ahí no había nadie, fui un sábado a la hora del aperitivo, cerca de la una o las dos, no había nadie.

En cambio, la Rambla del Poble $\mathrm{Nou}^{27}$, estaba llena de gente, porque es un eje cívico, es un eje peatonal, ¿Qué quiere decir un eje? ¿qué es un espacio público? es un elemento de conexión, y ¿qué es un espacio público lineal?, es un elemento de conexión entre diferentes partes, que además es peatonal, pues tiene las condiciones para poner terrazas, no hay coches, hay paz, los niños pueden correr, hay terrazas de bar donde la gente puede sentarse a tomar algo, estás sumando elementos positivos, hay sombra de los árboles, y sabes que es un eje histórico -pero esto no cuenta- sino que te lleva de un sitio a otro y que es como la espina dorsal del barrio, allí había gente.

También pasee por la remodelación de Pere IV y no había nadie, ¿Por qué? Porque a lo mejor era corta, porque aún le falta unirse, alargarse, pero por Pere IV no pasaba nadie, o igual fui en un momento equivocado.

Pero lo que sí te puedo decir es que la Rambla del Poble Nou, estaba llena de gente y en la Supermanzana no había nadie, entonces no puedes hacer una manzana Supermanzana con unos dibujitos en el suelo, pistas para correr, mesas de pingpong, yo creo que no, entonces para mí, ¿cuál es la oportunidad de la Supermanzana? Por un lado, evidentemente, quitar los coches, lo que decíamos también antes de aportar una identidad al barrio, si tú tienes unas calles normales del Eixample que pasan por ahí y las transformas en peatonales, pues haz un proyecto de espacio público, no diré que no se pueda pintar el suelo, pero que no es suficiente con esto, con esto no haces un espacio público, el espacio público es, según creo, el espacio público duro que es una calle, ¿Cómo puedes transformar? Pues qué se yo, a lo mejor, bueno con mi opinión es con

26.- El proyecto forma parte de los trabajos técnicos que se desarrollarán en torno a la redacción del Plan de Movilidad Urbana de Barcelona 2.013-2.018. El mapa de supermanzanas de Barcelona representa la nueva limitación de las células urbanas fruto de la definición de la nueva red ortogonal de autobuses de Barcelona.

Se trata de la elaboración de una propuesta de implantación del modelo de supermanzanas en cuatro ámbitos piloto dentro de la ciudad. Los ámbitos se localizan en los Distritos de Les Corts, Eixample y Sant Martí.

La propuesta se basa en las directrices de funcionalidad establecidas en el reciente Plan de Movilidad Urbana de Barcelona, donde la reestructuración de las redes de transporte público y bicicleta se basan en el modelo de supermanzanas.

El programa de supermanzanas supone para la ciudad de Barcelona beneficios en términos de movilidad sostenible, espacios ganados para plazas y espacios tranquilos, inclusión social, verde urbano y biodiversidad, optimización del uso de los recursos y gestión inteligente, entre otros aspectos.

BCNecologia (Agencia de Ecología Urbana de Barcelona)- consorcio público integrado por el Ayuntamiento de BarceIona, el Área Metropolitana de Barcelona y la Diputación de Barcelona- ha diseñado el proyecto. Nota del Editor 27.- Proyecto de J. Henrich, C. Hom, B. Martorell, C. Sanfeliu. 1991, 1999. Nota del Editor 


\section{on the w@terfront}

public art urban design civic participation urban regeneration

Urbanització de l'entorn de la Nau de Ca l'Alier i adequació de les zones verdes de la UA11 del peri Diagonal al districte de Sant Martí, 2013 J. Henrich amb S. Aires Marques, C.Boyer, Play-time
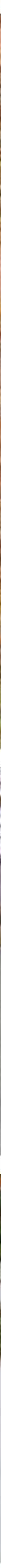
la vegetación, y luego introduciendo usos

como podía ser una plaza, como hacer una plaza, pero lineal, una calle. Entonces yo creo que muchas calles que se están haciendo ahora, de esas pequeñas, que se están peatonalizando, o se está reduciendo el uso del vehículo, muchas calles que son estrechas y se quita el aparcamiento en fila para ensanchar aceras y plantar una fila de árboles (es una tipología), son pequeños proyectos anónimos que habrás visto, anónimos de pequeña escala, que poco a poco van transformando los barrios, y está muy bien. Y en algunas hay, calzada deprimida, en otras, hay la calzada a nivel y se crea como un jardín, hay uno que está en el paseo de la Bonanova donde está el colegio de médicos, que es un sitio muy bonito que conecta con un jardín que hay más abajo, y han hecho una calle a nivel con unos grandes parterres y tal, es decir, es un buen ejemplo, es una buena vía para transformar una Supermanzana. Otra cosa es que la Supermanzana tuviera que tener algún equipamiento público, que ayudaría, pero por sobre todo lo que tendría que hacer es cómo conectarse con un sistema de espacios peatonales y transformarse.

Otro eje cívico que funciona muy bien, que es de los primeros, es Enric Granados, que es paralela a Balmes, y que es una calle que, al quitar el tráfico, que nunca ha tenido tráfico, ¿Por qué? Porque a lo mejor abajo no va a ningún sitio, porque llega a la Universitat y arriba se cortó en la Diagonal, ha tenido esta suerte que es un conector del barrio del Eixample, pero al no tener una permeabilidad, que está muy bien que no todas las calles pasen, igual que está muy bien que la Universitat corte la calle Enric Granados. No hace falta que todas las calles pasen, sí que tienen que pasar los peatones, y tú puedes acceder al jardín de la Universitat como peatón, entonces Enric Granados ha tenido esa condición, que siempre ha funcionado muy bien y se ha mejorado en los últimos años, han dejado un aparcamiento que yo creo que hay que quitar, porque el coche aparcado no tiene que estar en la calle, porque ensucia. $Y$ entonces las aceras más anchas, hay muchos restaurantes (se quejaban de que hay muchos restaurantes), hay terrazas _está bien, pero sobre todo porque no pasan coches a $50 \mathrm{~km} / \mathrm{h}$, esto cambia radicalmente todo. $Y$ eso es una medida.

Entonces, ¿qué es la Supermanzana? Para mí más que Supermanzanas, tendrían que hacer ejes cívicos así peatonalizados, y de estos ejes, a lo mejor se pueden enchufar, porque tiene que haber un elemento conector de calidad, se podían añadir Supermanzanas. Evidentemente la Supermanzana no tiene Pere IV, que, en teoría, no están remodelando en ese sentido, quizás le que falta Pere IV sea más larga y conecte un poquito más. Pero yo creo que esto de "vamos probando", "haremos unas correcciones", pero volveré, a lo mejor fui en un momento equivocado, pero vi que tenía las condiciones para no estar bien.

En su opinión, ¿Cuáles son los desafíos tiene Barcelona en cuanto a materia de Espacio Público? ¿Probablemente reducir aún más el vehículo privado?

No se hace nada para reducir el vehículo, en otras ciudades tienes que pagar, en Londres tienes que pagar un peaje si quieres circular, esto sería bastante disuasorio, yo creo que eso que decíamos 
del status. Luego hay mucha gente que se mueve en moto. Hay gente que no sale nunca de casa sin el coche o sin la moto. Ellos se desplazan, necesitan desplazarse. La gente que va en moto, son esa gente que van rápidos, hay gente que siempre sale de su casa con el coche. Esto hay que cambiar, esta mentalidad, esto es lo más importante, reducir el nivel de vehículos que hay, porque ocupan, ensucian y contaminan. A nivel concreto, acabar la Plaza de las Glorias, luego pues está el gran parque de La Sagrera que depende de los, que hay un proyecto, que también se hizo un, que puede estar muy bien, y que se suspende porque como depende del estado que se cubra todos los trenes, y el estado estamos como estamos, que si nos independizamos, si no nos independizamos, si invierten o si no invierten, es de esos proyectos que se puede eternizar mucho.

Aquí hay un aspecto que es también muy de Barcelona, que no sé si es una virtud o un defecto, es decir, que es dentro de esta dinámica de hacer cosas, hay un límite que es que a veces, quizás, es hacer demasiadas cosas, o se quieren hacer demasiadas cosas. Por ejemplo, creo que la Plaza de las Glorias, es otra de los proyectos que no se han hecho bien, o lo que se hizo, -con todo respeto a los autores que son también conocidos-, en la Gran Vía ${ }^{28}$ a partir de la Plaza de las Glorias hacia el norte, no se hizo bien, es un mal proyecto.

Eso quiere decir que en Barcelona parece que todo se haga bien, no, yo también he cometido errores, no sé si tan grandes como estos, no. En Barcelona también había o hay varios departamentos pensantes, entonces había cabezas que no han llegado nunca a entender lo que es el espacio público, a pesar de que mandaban y actuaban. Entonces el proyecto de la Gran Vía, está mal, que quiere decir que a veces se hacen demasiadas cosas, por ejemplo, ¿Hacía falta hacer un túnel en la Plaza de las Glorias? O, ¿se tenía que bajar no sé cuántos metros, que va costar millones y millones, con los que se podían hacer sin hacer demagogia 33 escuelas? A lo mejor, a lo mejor nos estamos pasando, a veces, porque si los coches que van por la Gran Vía llegan a la Plaza de las Glorias, ¿No se pueden desviar a $50 \mathrm{~km} / \mathrm{h}$ o si quieres a $30 \mathrm{~km} / \mathrm{h}$, igual que dan la vuelta a la Plaza Cataluña? ¿No molesta en la Plaza Cataluña que haya coches alrededor? Es lo que hay, intentemos que haya el mínimo de coches, hagamos las calzadas estrechas, ¿Hacía falta que baje un túnel? en medio de la obra tuvieron que pararla porque tenía que bajar aún mucho más. Si vas a París, por ejemplo, que llegó el tren de alta velocidad, ellos no han construido ninguna estación nueva, ellos utilizan las estaciones que tenían, para el TGV, que tienen muchas, vale, que les haya ido muy bien, perfecto, pero no hay ningún tren que atraviese París. Aquí tuvo que atravesar Barcelona, pasa por delante de la Sagrada Familia, todas las complicaciones, entonces no sé cuantos meses de nuestras vidas que teníamos que estar pendientes si caía la Sagrada Familia o no se caía. ¿Qué igual ha pasado? ¿Qué igual podía pasar por detrás del Tibidabo e irlo a coger a Sant Cugat, por decir algo? igual no. Luego esto de La Sagrera que está muy bien, tapar todas las vías y crear un parque, pero eso está ahí, hace no sé cuántos años, ojalá y espero que se resuelva, porque es algo bueno para Barcelona. 
Pero todo lo que depende del Estado Español, que es malo, en el sentido que no invierte en sus compromisos. Pues estamos pendientes de cosas que deben llevar ya 5,6,7,8 años planificadas y no se ejecutan, porque son obras un poco, digamos faraónicas, ese es el extremo un poco, el límite.

Ojo también con esta tendencia de querer resolverlo todo, por ejemplo la Ronda del Mig, por ejemplo, que nosotros pensábamos que podía llegar a la Diagonal, hicimos un proyecto que llegaba hasta la Diagonal, porque conectaba el paseo de la Diagonal con el Paseo del Mig, tenía su lógica, en un momento dado dijeron no se cubre más, porque por un lado hubo un accidente en el túnel de Montblanc, que utilizaron para decir "esto de los túneles puede ser peligroso", por tanto no cubrimos más, pero por otro lado, luego al cabo de los años, porque ha cambiado la gente, se hace el túnel de las Glorias, ¿por qué se planteó el túnel de las Glorias? Seguramente fue un peaje, como estaba el anillo, a los vecinos que estaban rebotados con el anillo, fue alguien que hizo la concesión del túnel. Así como te digo, los trenes tienen que ir por debajo evidentemente, los coches yo creo que es una plaza suficientemente grande que evidentemente estará mejor sin los coches, sin duda, pero yo creo que es exagerado el coste, este es como un límite faraónico.

\section{¿Qué opinión tiene sobre el papel de las Universidades en la creación de Espacios Públicos?}

¿En la creación de espacios públicos o en generar conocimiento? Hay a veces unas propuestas de concursos del Área Metropolitana para jóvenes arquitectos para resolver proyectos, di clases en un Máster de Urbanismo, que tenían intereses que se trabajase en el espacio público, a veces voy a las correcciones de los proyectos.

Hay una preocupación por el espacio público, pero no tanto como disciplina en sí. He visto proyectos y he asistido a proyectos de urbanismo y de arquitectura, donde el espacio público no se tenía en cuenta, sino que estaba un poco castigado. Por ejemplo una vez fui a una corrección donde estaban trabajando la Plaza de las Glorias, y estaban construyendo edificios en medio, porque alguien pensó que era demasiado grande o alguien que hizo un ejercicio que lo vi en internet, nuevas viviendas en la Barceloneta, en el Paseo Marítimo, en las plazas que son más o menos triángulos irregulares, unos edificios muy estilosos así de buena arquitectura, que estaban negando el espacio público, suerte que no estoy en la Escuela o si no me ponía nervioso. Esto no quiere decir que no se tiene en cuenta, pero son ejemplos contrarios.

No conozco el detalle, pero sí que hay en las Universidades, hay Máster de Diseño Urbano: Arte, Ciudad y Sociedad y el Máster de Paisajismo, que tratan temas de espacio público y de paisajismo como especialidad.

Muchísimas gracias arquitecto por su valioso tiempo, y esperamos algún día que Ud. pueda trabajar en mi ciudad Asunción, Paraguay o en alguna colaboración, porque en mi ciudad lo que es de todos, no es de nadie, necesitamos buenos arquitectos que nos ayuden a diseñar los espacios públicos de calidad que tanta falta hacen. 


\section{on the w@terfront}

public art urban design civic participation urban regeneration
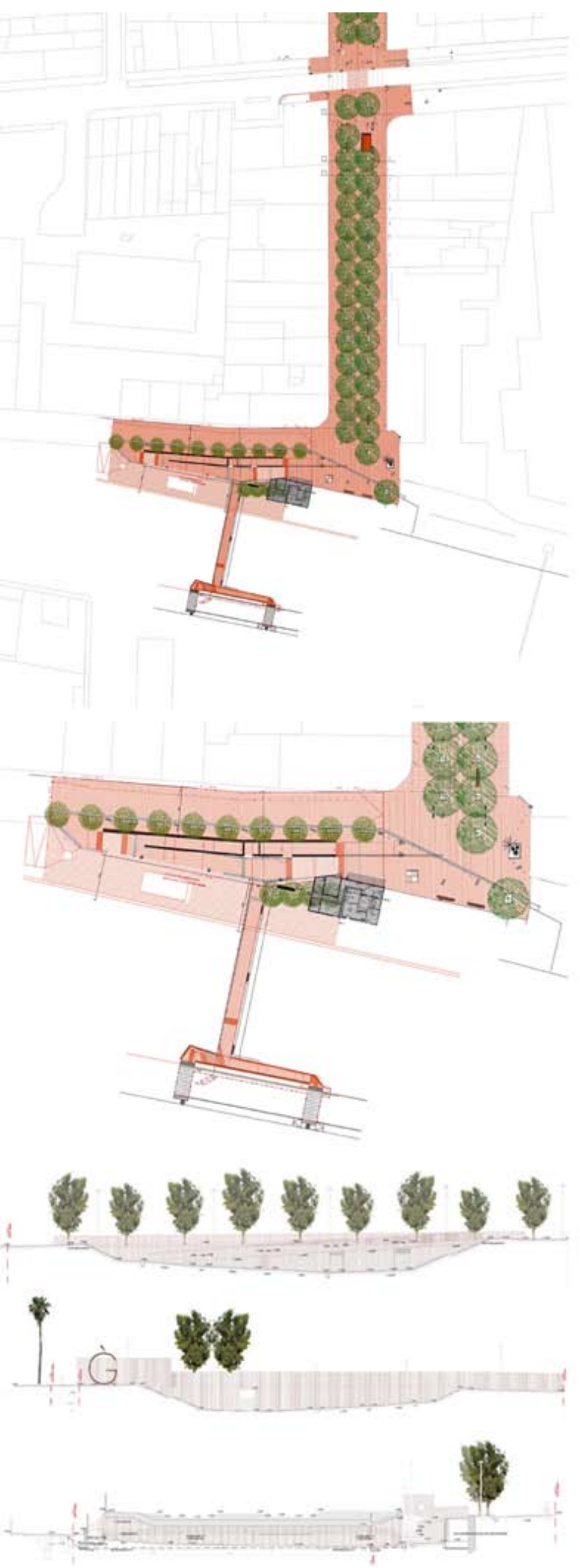

DOI: https://doi.org/10.1344/waterfront2019.61.6.7

Accés a refugi soterrani i a pas inferior, Rambla de Gavà - fase 32012

J. Henrich amb J.Megías, S.Scarano, O.Cabrera, V.Porcar, F.Reyes
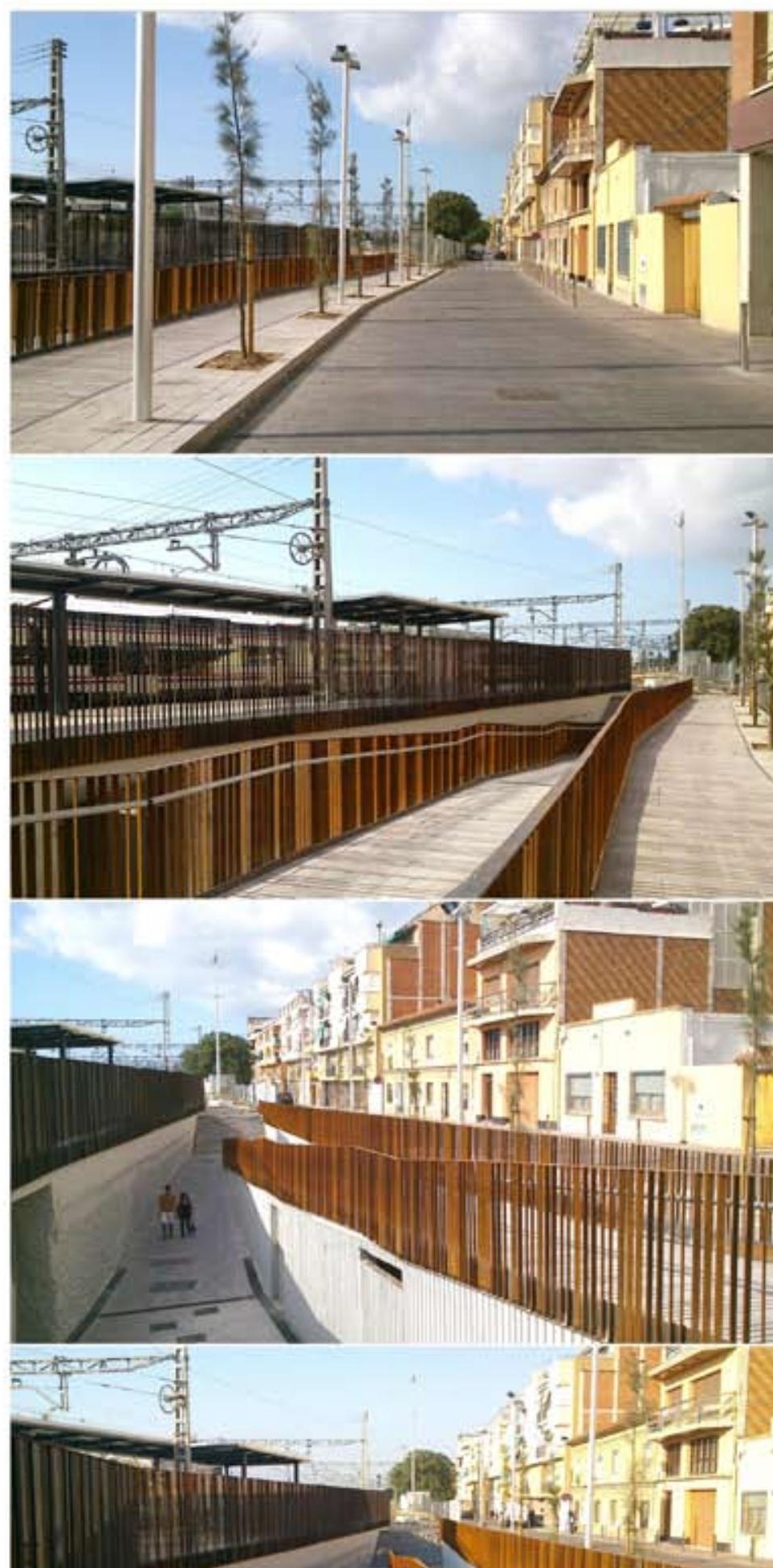
Lo importante es tener alguien que tenga la capacidad de pensar esta ciudad, de una manera, en el tiempo, planificando los próximos 4-8 años, pero pensando que esto será un proceso de 40 años, vamos a empezar, y vamos a empezar con proyectos realizables, y vamos a empezar con proyectos que sean estratégicos y que a lo mejor sean en el centro o cerca del centro, o en ese barrio, trabajando con diferentes tipologías complementarias y que sean viables y realizables en 3-4 años. Y empezando así.

Entonces vas estableciendo, poco a poco, una cultura y una visión de que todos los ciudadanos y los políticos sobre todo ven que esto ayuda a transformar la ciudad. Yo creo que esto es un tema que en Latinoamérica en general, alguien que tenga el conocimiento, un poco la visión global, puede llegar a introducirlo en la Administración, a veces parece que no os preocupe, con tantos problemas, pero la identidad de una ciudad, es su base, lo que decíamos, es su mejor argumento, lo que es ponerse en valor, para todos los habitantes incluso para los visitantes, pero sobre todo para los habitantes, tiene que haber alguien que tenga esa visión global, pero al mismo tiempo atenta, que es lo yo creo que es lo que tenemos en general los arquitectos, que tenemos esta profesión, pero sobre todo también como tú decías en tus preguntas, capaces de generar equipos de expertos en ingeniería, en temas de movilidad, en temas de infraestructuras urbanas, en temas de todo tipo de infraestructuras, porque el proyecto de espacio público tiene que guiar todos estos temas técnicos, y alguien tiene que empezar a hacerlo. ¿Cómo se hizo en Barcelona? Se creó una Oficina de Proyectos Urbanos, con arquitectos jóvenes que ni acabaron la carrera o estaban acabando la carrera, que empezaron a hacer algunos proyectos, luego se organizaron algunos concursos, el de las plazas de Gracia, por ejemplo, o pequeños parques en antiguas fábricas, todo esto es como inicio, en antiguas fábricas, la Pegaso ${ }^{29}$, la España Industrial ${ }^{30}$, zonas que eran antiguas industrias. Se hacen parques, y este fue un poco el inicio, el parque del Escorxador ${ }^{31}$, que antes era el matadero. Esto muchas ciudades seguramente lo han continuado con todas las variantes que quieran.

Este fue un poco el inicio, y confiar un poco en ese tiempo en los técnicos que había y sobre todo, yo creo, que fue la mente clara de Bohigas, que a lo mejor, ¿ cha hecho proyectos de espacio público Bohigas? No lo sé, pero él hablaba de esta cultura o esta tradición que se había perdido, que por un lado seguramente era la ingeniería de las calles bien hechas, como la calle Ferrán antigua de piedra, o como se hacían las calles del Eixample, con las aceras de $5 \mathrm{~m}$, la mitad para el peatón y la mitad para el vehículo, $5 \mathrm{~m}-10 \mathrm{~m}-5 \mathrm{~m}$, con la estructura de aceras y arbolados, con hacer los chaflanes, que ordenaban Barcelona, un proyecto de ingeniería civil aplicado a la ciudad, o la tradición paisajística que aquí no es muy grande, pero que tenemos algún ejemplo como los jardines de Montjuic, los jardines del Laberinto de Horta, que son elementos de paisajismo, pero que no había una cultura de espacio público, entonces fijate que incluso al principio al no haber esta cultura, muchos arquitectos se encontraban limitados y empezaban a salir pérgolas, porque si no hacías pérgolas, esto de hacer un bordillo parecía que era poca cosa.

29.- Proyecto de E. Batlle, J. Roig, 1986. Nota del Ed.

30.- Proyecto de Luís Peña Ganchegui, F. Rius, 1985. Nota del Ed.

31.- Proyecto de A. Solanas, A. Arriola, B.Galí, M. Quintana, 1985. Nota del Ed. 
Espais Públics de Bocana Nord, Port de Barcelona

J. Henrich con JM Mayol, N. Mayol, D. Pino, D. Carrascal, S. Ros (APB), C. Arrarte, E. Negro, Payma - Cotas (en construcción)
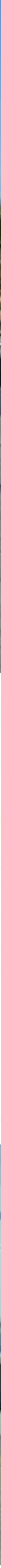

48

(c) (1) 
Esto por un lado, pero luego yo creo que la madurez del espacio público vino en obras como la Plaza de la Catedral o la Rambla de Cataluña ${ }^{32}$, ¿Qué tuvo la Rambla Cataluña? que fue la primera calle donde se implementaron los vados de acceso para los minusválidos y para todo el mundo, el vado 120, se ampliaron las aceras laterales, se reconstruyó de manera sobria, se quita el autobús que está castigando este eje tan bonito y se pasa por el Paseo de Gracia que tiene toda la capacidad, eso es una pequeña lección, el autobús no va por donde quiere, como es público, tú ahora pasas por aquí, se organiza todo, todo va ligado.

Y estos proyectos de los años 1980 representan la madurez de ese espacio público, y en esta época:1980 principios de los 1990.Se estableció, también, el Departamento de Elementos Urbanos, donde se sistematizó, por un lado estos vados 120, los accesos de los aparcamientos con la cajita de vidrio, ascensor y escalera, las ventilaciones, todo integrado, las barandillas de vidrio que parecía que se iba a romper y al final han funcionado muy bien y se han extendido a toda la ciudad.

Esto es un ejemplo que se ha ido extendiendo en toda la ciudad. Los bordillos eran manuales al principio, luego mecanizados (ia finales del siglo XX!), las ventilaciones de los parkings, la señalización de los metros, todo esto, la iluminación, los bancos, los quioscos de prensa, la estandarización y sistematización de todos los elementos urbanos con este criterio de sobriedad y minimalismo.

Los quioscos están muy bien en Barcelona, hay otros sitios donde son historicistas, antiguos. Las marquesinas de autobús, las amarillas, originales, el OPI, que se inventó aquí, con la marquesina del autobús, el elemento este de publicidad vertical, luego la marquesina de Foster que es aquella de color color gris, lo introdujo, pero el primero aquí yo creo que era de aquí. Luego en algunas estaciones de metro, ya habían algunos elementos de señalización, pero el de la publicidad, que además se va renovando y que es de calidad y hay alguien que hace el mantenimiento, lo cambia cada 15 días, lo que sea, esto es un invento de todo esto, los quioscos de los parques, el quiosco Habana, todos los vados, y esto conforma la cultura del espacio público, y si se ha hecho bien la Diagonales, también, porque ya había una cultura del espacio público, porqué ya había unos bordillos, ya había unos vados, hay bordillos hechos de 40, el vado en lugar de 120, hay de 160 , o de $2 \mathrm{~m}$. Es decir, en la calidad del trazado geométrico acompañada de la calidad de materiales es un producto de esta experiencia y también de que ha habido en esta experiencia un Departamento de Elementos Urbanos que lo ha ido manteniendo, quizá se creó y hubo un momento muy brillante y luego ahora se va manteniendo.

Pero digamos que en Barcelona hay mucho control de todo. $Y$ esto creo que es lo que se puede organizar en una ciudad que tenga digamos una historia y tenga ganas de ponerse en valor.

32.- Proyecto de M. Quintana, R. de Cáceres y J.Graells, 1990. Nota del Editor 


\section{REFERENCIAS}

BOHIGAS, O- TUSQUETS, O. 1986. Diàlegs a Barcelona. Barcelona: Editorial Laia.

Bohigas, O- Puigdomenech,A- ACebillo, J- Galofré, J. 1983. Plans i Projectes per a Barcelona 1981/1982. Barcelona: Ajuntament de Barcelona. http://cbab.bcn.cat/uhtbin/cgisirsi/0/x/0/57/28/686/X?user_id=INTERCAT.

BOHIGAS, ORIOL. 1985. Reconstrucció de Barcelona. Llibres a I'Abast. Barcelona: Edicions 62.

BOHIGAS, ORIOL. 2004. Contra la Incontennecia Urbana. Reconsideració moral de l'arquitectura i la ciutat. Barcelona: Diputacó de Barcelona.

BORJA, JORDI. 2009. Luces y sombras del urbanismo de Barcelona. Barcelona: Editorial UOC-El Ciervo 96, S.A.

BORJA, JORDI (ED). 1995. Barcelona: un modelo de transformación urbana. Quito: Progr ama de gestión Urbana (PGULAC).

Cáceres, Rafael, y Ferrer, Montserrat. 1993. Barcelona, espacio público. Barcelona: Ajuntament de Barcelona. http:// cbab.bcn.cat/uhtbin/cgisirsi/0/x/0/57/28/686/X?user id=INTERCAT.

CAPEL, HORACIO. 2005. El Modelo Barcelona: un exámen crítico. Barcelona: Ediciones del Serbal.

DOMÈNECH I MONTANER, LLUIS. 1878. «En busca de una arquitectura nacional». La Renaixensa, any 81 (4, 28 febrer de 1878): 149-60.

El HaddAd, MARIE. 2017. «Barcelona: Small-Scale Public Spaces». Doctoral, Barcelona: Universitat de Barcelona. http:// www.tdx.cat/handle/10803/455143.

Esparza LozAno, Danae. 2017. Barcelona a ras de suelo. Comunicación Activa/ Ciudad 17. Barcelona: Edicions de la Universitat de Barcelona.

FAVB (Federació de Veins de Barcelona). 1997. La Barcelona de Maragall. Barcelona: CAVE.

FLORENSA, AdOLF. 1958. Nombre, extensión y política del «Barrio Ggótico»>. Barcelona: Ayuntamiento de Bacelona.

Fuster, J- Nicolau, A-Venteo, D. 2001. La construcció de la gran barcelona: L’Obertura de la ViaLaietana, 1908-1958. Barcelona: MUHBA- Ajuntament de Barcelona.

GATCPAC. 1931. «Respetamos la buena arquitectura del pasado». A.C. Documentos de Actividad Contemporánea, n. ${ }^{\circ}$ 2: 22-23.

HENRICH, JORDI. 2017. «Recuperació del frontportuari de Barcelona i marítim de la Barceloneta». En In Corbella, $D(E d)$ L'aigua i l'espaipúblic. Anàlisidelsefectes del canviclimàtic., 53-72. Barcelona: Edicions de la Universitat de Barcelona.

LECEA, I DE- HENRICH, J. 2002. «Barcelona. espaisurbans 1981-2001». Ajuntament de Barcelona. http://cbab.bcn.cat/ uhtbin/cgisirsi/fKu7cSPJQM/BG/55110004/9.

LECEA, IGNASI DE. 2006. «Sobre el proyecto del suelo». On the w@terfront [en línia], 2006.

MARAGALL, PASCUAL. 1991. Barcelona, la ciutat retrobada. Barcelona: Edicions 62.

MCNEILL, DAVID. 1999. Urban Change and the EuropeanLeft. Tales from the New Barcelona. Londres: Routledge.

Molx, Llatzer. 1994. La ciudad de los Arquitectos. Barcelona: Anagrama.

Molx, LlatZer. 2010. Arquitectura Milagrosa. Hazañas de los arquitectos estrella en la España del Guggenheim. Barcelona: Anagrama.

Monclús, FCO. JAVIER. 2005. «El Modelo Barcelona, ¿Una fórmula Original? de la "Reconstrucción" a los Proyectos urbanos estratégicos (1997-2004)». Perspectivas Urbanas, 2005. http://www.raco.cat/index.php/Perspectivas/article/ view/84991 [Consulta: 09-01-17].

Montaner, J.M.- Alvarez, F- Muxí, Z (ED). 2011. Archivo Crítico Modelo Barcelona, 1973-2004. Barcelona: Ajuntament de Barcelona.

Moure, Gloria. 1994. Configuraciones Urbanas. Ediciones Polígrafa,S.A. Barcelona.

Norbert-Schulz, Christian. 1980. Genus Loci, Towards a phenomenologyofarchitecture. New York: Rizzoli.

REMESAR, A. 2013. «Barcelona: Un modelo de Arte Público y Diseño Urbano». En in HAMANN, Johana (ED) LIMA: ESPACIO PÚBLICO, ARTE Y CIUDAD, 13-54. Lima: Pontificia Universidad Católica del Perú.

Ríos DíAz, MARIEN. 2017. «¿Hacer Ciudad? Barcelona, la construcción del paisaje, 1929-1973». Doctoral, Barcelona: Universitat de Barcelona. http://hdl.handle.net/10803/481954.

SUBIRós, PEP (ED). 1993. El vol de la fletxa. Barcelona 92'. Crònica de la reinvenciód’unaciutat. Barcelona: Electa. TATJER, MERCÈ. 2000. «Las intervenciones urbanísticas en el centro Histórico de Barcelona: De la Vialaietana a los nuevos programas de rehabilitación». En Bernal Santa Olalla, B (Coord) Oportunidade de desarrollo sostenible para los conjuntos urbanos históricos. III Jornadas de geografía Urbana (Burgos 18 a 21 mayo 1998), 13-28. Burgos: Servicio de Publicaciones de la Universidad de Brugos. http://www.ub.edu/geocrit/sv-106.pd.

\section{RECONOCIMIENTOS}

Este trabajo ha sido realizado en el marco del Programa Nacional de Becas de Postgrado en el Exterior "Don Carlos Antonio López", del Ministerio de Hacienda del Paraguay. 